STONE CENTER ON SOCIO-ECONOMIC INEQUALITY

WORKING PAPER SERIES

No. 23

Epidemics, Inequality and Poverty in Preindustrial and Early Industrial Times

Guido Alfani

October 2020

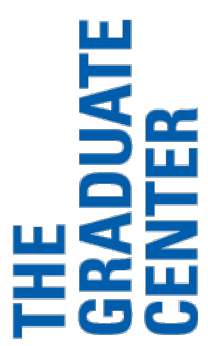

CITY UNIVERSITY

OF NEW YORK 


\title{
Epidemics, inequality and poverty in preindustrial and early industrial times
}

\author{
Guido Alfani*
}

\begin{abstract}
:
Recent research has explored the distributive consequences of major historical epidemics, and the current crisis triggered by Covid-19 prompts us to look at the past for insights about how pandemics can affect inequalities in income, wealth, and health. The fourteenth-century Black Death, which is usually believed to have led to a significant reduction in economic inequality, has attracted the greatest attention. However, the picture becomes much more complex if other epidemics are considered. This article covers the worst epidemics of preindustrial times, from Justinian's Plague of 540-41 to the last great European plagues of the seventeenth century, as well as the cholera waves of the nineteenth. It shows how the distributive outcomes of lethal epidemics do not only depend upon mortality rates, but are mediated by a range of factors, chief among them the institutional framework in place at the onset of each crisis. It then explores how past epidemics affected poverty, arguing that highly lethal epidemics could reduce its prevalence through two deeply different mechanisms: redistribution towards the poor, or extermination of the poor. It concludes by recalling the historical connection between the progressive weakening and spacing in time of lethal epidemics and improvements in life expectancy, and by discussing how epidemics affected inequality in health and living standards.
\end{abstract}

JEL Codes: ～D31, D63, I14, I30, J11, N30, N33)

*Guido Alfani (guido.alfani@unibocconi.it) is affiliated with Bocconi University, Dondena Centre and IGIER. Milan (Italy) and the Stone Center for Research on Socio-Economic Inequality, at the Graduate Center of the City University of New York (U.S.). Alfani is grateful to Noel Johnson, Mark Koyama and Stefano Mazzuco for many helpful comments; to Mattia Fochesato and Şevket Pamuk for providing him with their data about real wages for various cities and areas, to Leandro Prados de la Escosura for having shared data about Spain, and to Jean-Laurent Rosenthal and Gilles Postel-Vinay for having shared data and information about inequality in nineteenth-century France. The research leading to this article has received funding from the European Research Council under the European Union's Seventh Framework Programme (FP7/2007-2013)/ERC Grant agreement No. 283802, EINITE-Economic Inequality across Italy and Europe, 1300-1800 as well as under European Union's Horizon 2020 Framework Program/ERC Grant agreement No. 725687, SMITE-Social Mobility and Inequality across Italy and Europe, 1300-1800. 


\section{Introduction}

There is a growing concern about the possible distributive consequences of the ongoing Covid-19 pandemic, which has prompted many to look at past experiences for insights. In this perspective, studies of inequality trends in the very long run of history, which have flourished in recent years, have attracted particular attention. A characterizing feature of many such studies, especially those that also cover the preindustrial period, is that they tend to underline the role played by major pandemics, and particularly by the fourteenth-century Black Death, in producing macroscopic distributive effects on both income and wealth. Based on the example of the Black Death, the view that pandemics had the power to (brutally) level inequality has become quite widespread. Much less attention has been paid to smaller-scale, but more frequent, epidemics. There are two main reasons for this. The first is technical, and is related to the kind of historical documentation which is available for relatively remote epochs - a documentation which very often allows us to detect major perturbations of the overall trend only, leaving in the dark smaller fluctuations as well as the fine details of the distributive dynamics. The second is that truly, as far as we know today, only major pandemics like the Black Death and more generally, catastrophes on an exceptional scale seem to have left a dent in what was, otherwise, a very stable distribution of income and economic assets (Alfani 2017; 2020a; Milanovic 2016; Scheidel 2017) ${ }^{1}$. And yet, for the epochs when we have enough information to analyze changes across the entire distribution, some studies, while reporting very limited reduction in inequality for even the worst episodes, have explored the circumstances that prevented pandemic leveling from happening time and again, focusing in particular on the institutional framework in place at the onset of the crisis (Alfani 2010; 2020a; Alfani and Di Tullio 2019; Van Bavel 2020). By highlighting the factors that have shaped how pandemics and major epidemics could lead to radically different distributive consequences, these studies are maybe of greater help for understanding how the current crisis caused by Covid-19 can be expected to affect inequality.

Looking more closely at how past epidemics shaped the distribution of income and wealth across society also allows us to answer different questions. A particularly notable one is how epidemics affected the poorest part of the population. This issue, which is only now emerging in the literature on preindustrial epidemics, is of particular import today given the widespread concerns that Covid-

\footnotetext{
${ }^{1}$ Stable, bar for a tendency towards slow but continuous inequality growth: Alfani 2017; $2020 \mathrm{a}$.
} 
19 might disadvantage the poor in two different ways. First, by affecting them more than other social-economic strata (permanently ruining their health or killing them outright with greater-thanaverage frequency). Secondly, by causing them greater direct economic damage, for example by leading to unemployment or to significant wage reductions for low-skill workers. Indeed, the way in which preindustrial epidemics affected real wages and the labour market more generally is the focus of many recent studies (Pamuk 2007; Pamuk and Schatzmiller 2014; Fochesato 2018; Alfani and Percoco 2019; Rota and Weisdorf 2020).

Looking at poverty in the past allows us to underline another fact which is often neglected: highly lethal pandemics can reduce inequality not only through redistribution, but also through extermination of the poor (Alfani and Di Tullio 2019; Alfani 2020b; Alfani, Ammannati and Ryckbosch 2020). This fact, which is heavily dependent upon selectivity by status of specific pathogens, is not only relevant for early modern plagues, but continued to play a role into the nineteenth century, when a new disease spread across the world: cholera. For this reason, this article will focus mostly on plague and cholera and will push into the nineteenth century, hence covering early industrial as well as preindustrial societies. Although both plague and cholera led to much higher mortality rates than we currently expect from Covid-19, some aspects remain very relevant: namely the way in which government action either led to policies that increased mortality among the poorest (hence strengthening the social connotation of an epidemic), or laid the foundations for a lasting improvement in their health and living conditions. The first case was common in the age of plague, while the latter tended to characterize the age of cholera.

In many respects, the nineteenth century was an age of transition. It was the period when the first industrial societies emerged or (in the rare cases of early developers like England) consolidated. In a scholarly tradition started by Robert Fogel $(1994 ; 2004)$, this was a crucial phase for humanity's (still incomplete) escape from hunger and premature death. It was also the period when, after an initial worsening, substantial achievements were obtained in improving health conditions across many societies and in reducing health inequalities (Deaton 2003; 2016). If we measure these achievements in terms of life expectancy at birth, the reduction in the deaths caused by infectious disease is well-known to have played a crucial role. A key component of this process is the decline in the frequency and severity of acute episodes (i.e. of lethal epidemics and pandemics, particularly those caused by plague) which occurred from the late seventeenth century 
(Livi Bacci 2000; 2017). Also from this point of view, the historical experience offers an important reminder of what is at stake - as there is reason to worry that new pandemics caused by infectious diseases might lead to increases in dimensions of inequality beyond income and wealth, including in particular health. This may be especially true in those countries where access to good-quality health services is uneven across social strata, which often coincide with those where worries for growing health inequality had been spreading even before the appearance of Covid-19 (for example, Case and Deaton 2015; 2017).

The article is structured as follows. Section 2 analyzes in detail the case of the Black Death of 1347-52, the prototypical leveling pandemic, and also provides a brief discussion of the distributive consequences of Justinian's Plague of 540-41 and of the string of epidemics which led to the demographic collapse of Latin America after the Conquest. Section 3 focuses on later episodes, from the European plagues of the seventeenth century to the cholera pandemics of the nineteenth, and explores the factors (institutional and other) that prevented even major events from leading to inequality reduction on a scale comparable to the Black Death. Section 4 focuses on poverty, discussing the issue of selective mortality by social-economic status and exploring the different channels through which epidemics could lead to reduction in the prevalence of the poor (redistribution towards the poor vs extermination of the poor). Section 5 concludes, highlighting the importance of the progressive weakening and spacing in time of lethal epidemics in leading to substantial improvements in life expectancy and more generally, how epidemics affected inequality in health and living standards.

\section{The Black Death: a Great Leveler?}

The last few years have seen a surge in new research about preindustrial inequality, which has greatly increased the amount of information (collected from the surviving archival sources) that we can use to reconstruct long-term trends in income and, more frequently, in wealth inequality. An updated survey of this research and of the related literature is offered elsewhere (Alfani 2020a). Overall, the new evidence suggests that in preindustrial times economic inequality was subject to a creeping tendency towards inequality growth - with the exception of a few episodes of sudden inequality reduction. Pandemics and large-scale epidemics play a crucial role in this story because of the fourteenth-century Black Death. However, recent research has significantly expanded the 
coverage of past pandemics and epidemics as the possible trigger of large-scale redistribution. The aim of this section and the next is to provide a detailed overview of this literature and to show how actual dynamics are indeed more complex than one could presume based exclusively on the case of the Black Death. Before doing that, however, we need to describe the kind of events that we are interested in.

\subsection{Epidemics, pandemics and the Black Death: some preliminary clarifications}

It is useful to recall the difference between "epidemics" and "pandemics". An epidemic occurs when cases of an infectious disease become more widespread in a given population at a particular time with respect to the long-term prevalence of such disease. The word "pandemic" refers to epidemics that cover multiple continents or that spread worldwide (Last 2001). Hence for example, the Black Death of 1347-52, each one of the six cholera waves that occurred in the period 18171923, and the Spanish Flu of 1918-19 can all be properly characterized as pandemics and obviously the same is true for Covid-19. Importantly, pandemics do not differ from epidemics because of higher mortality rates or absolute number of victims, but just because of their ability to spread across very large areas and to infect many people. Some recent pandemics (like the Swine Flu of 2009-10) were characterized by very low case fatality rates, while some epidemics, like Ebola in 2013-16, proved highly lethal and claimed a large number of victims in the areas affected, but were not able to spread much further beyond the original areas of infection and never became pandemics.

This article will focus on the distributive impact of epidemiological events that were exceptionally severe in terms of the proportion of the population they killed (i.e., the 'mortality rate') or of the overall number of victims. There are two main reasons for this. The first has to do with the intrinsic limitations of the information that we have available: before the sixteenth or even the seventeenth century only truly major events, like the Black Death, generated an amount of (surviving) documentation sufficient to provide us with the evidence needed to explore epidemic-triggered distributive dynamics. The other reason is more substantial: from the early modern times, when for some world areas (mostly, but not exclusively, in Europe) we have, at least on principle, the possibility of looking in detail at how epidemics affected economic structures and influenced the 
distribution of wealth and income in the short, medium and long run, we find that only the most severe epidemics had consequences visible at a macro level, and such consequences were invariably on a scale much lower than that reported for the Black Death. Indeed, as will be seen, one of the ways in which the terrible pandemic of the fourteenth century was able to produce enduring economic consequences was by triggering a process of institutional adaptation that made the distribution of resources across society much more resilient to mortality shocks - in a way which purposefully tended to preserve the status quo ante and the interests of the economic elites. The exceptional nature of the Black Death is showcased by its relative position in the grim roster of the worst (known) pandemics in human history. It was an outbreak of plague, an infection caused by the Yersinia pestis bacillus, which after having started in China or in some other part of Asia reached Europe in late 1347. In Europe and the Mediterranean, during 1347-52 the Black Death caused up to 50 million victims, to which we should add difficult-to-quantify numbers in the Middle East, central Asia, and possibly parts of China, of sub-Saharan Africa, and others (Alfani and Murphy 2017; Green 2015; 2018). If we look at the number of victims, only the Spanish Flu is considered to have possibly caused more: from a minimum of 50 to a maximum of 100 million deaths worldwide depending on the estimate (Johnson and Mueller 2002), although probably the real toll is closer to the lower than to the upper boundary (Barro, Ursua and Weng 2020). However, in terms of mortality rates the Black Death was orders of magnitude worse than the Spanish Flu. In Europe and the Mediterranean, it killed about half the overall population, up to an estimated maximum of $60 \%$. From this perspective, the Black Death clearly stands out as "the" worst pandemic in human history and it should be no surprise that it is usually believed to have had the strongest economic impact as well. Interestingly, another plague pandemic ranks immediately after the Black Death in terms of both overall number of victims and mortality rates: Justinian's Plague of 540-41, which caused 25-50 million deaths in Europe and the Mediterranean area $(25-50 \%$ of the overall population; probably very close to the upper boundary in Egypt and in other densely populated areas) (Alfani and Murphy 2017, pp. 315-319)2.

\footnotetext{
${ }^{2}$ Note that, to complicate matters, in the plague literature the term "pandemic" is also used to distinguish between a "First Pandemic", which would have started with Justinian's plague of 540-41 but would have included a series of outbreaks until around 750, when the infection disappeared from Europe and the broader Mediterranean area, and a "Second Pandemic" which started with the Black Death but also included a string of later outbreaks that ended only in the early nineteenth century (Kohn 2007; Little 2007; Alfani and Murphy 2017). Finally a "Third pandemic" originated in China, in the Yunnan area, towards the end of the nineteenth century and is still ongoing (Ziegler 2015; Alfani and Murphy 2017; Welford 2018). In this article, when referring to plagues the term "pandemic" will be used
} 


\subsection{Wealth and income inequality decline after the Black Death: the evidence}

The amount of data that we have available about the direct redistributive consequences of the Black Death has increased in recent years. This evidence points in a very coherent way towards a strong ability of such a pandemic to cause a marked drop in wealth inequality. For no world area are data more abundant than for the Italian region of Tuscany. A recent study based on property tax records known as estimi reported that across a sample of two cities (Prato and San Gimignano) and three rural communities for which pre- and post-Black Death information was available, wealth inequality suffered a marked contraction (Alfani and Ammannati 2017). Still-ongoing research has added to the picture ten additional rural communities from the countryside under the domination of Florence, and in each single one a steep decline in wealth inequality after the Black Death has also been found (Alfani, Ammannati and Balbo 2020). As an example, Figure 1 shows the trends in wealth inequality (Gini indexes) in two communities for which particularly good and frequent information is available: the city of Prato and the rural village of Santa Maria Impruneta. As the second had limited size (about 120 households before the Black Death, falling to 82 in 1350 and slowly recovering the pre-plague level in the following decades), there might be some doubts about the statistical significance of the reported changes in the Gini level. Therefore, Figure 1 also includes $95 \%$ confidence intervals calculated by bootstrap methods ${ }^{3}$.

for the Black Death and for Justinian's Plague only, while all other plague outbreaks will be referred to as "epidemics". This, also to ensure the use of a coherent terminology when comparing plague and cholera.

${ }^{3}$ About bootstrap methods applied to measurement of historical inequality, see Steckel and Moehling 2001 and Santiago-Caballero 2011; about their application to medieval property tax records and about their intrinsic virtues and limitations, see Alfani 2020a. 
Figure 1. Wealth distribution in medieval Tuscany, ca. 1300-1430 (Gini indexes with 95\% confidence intervals)

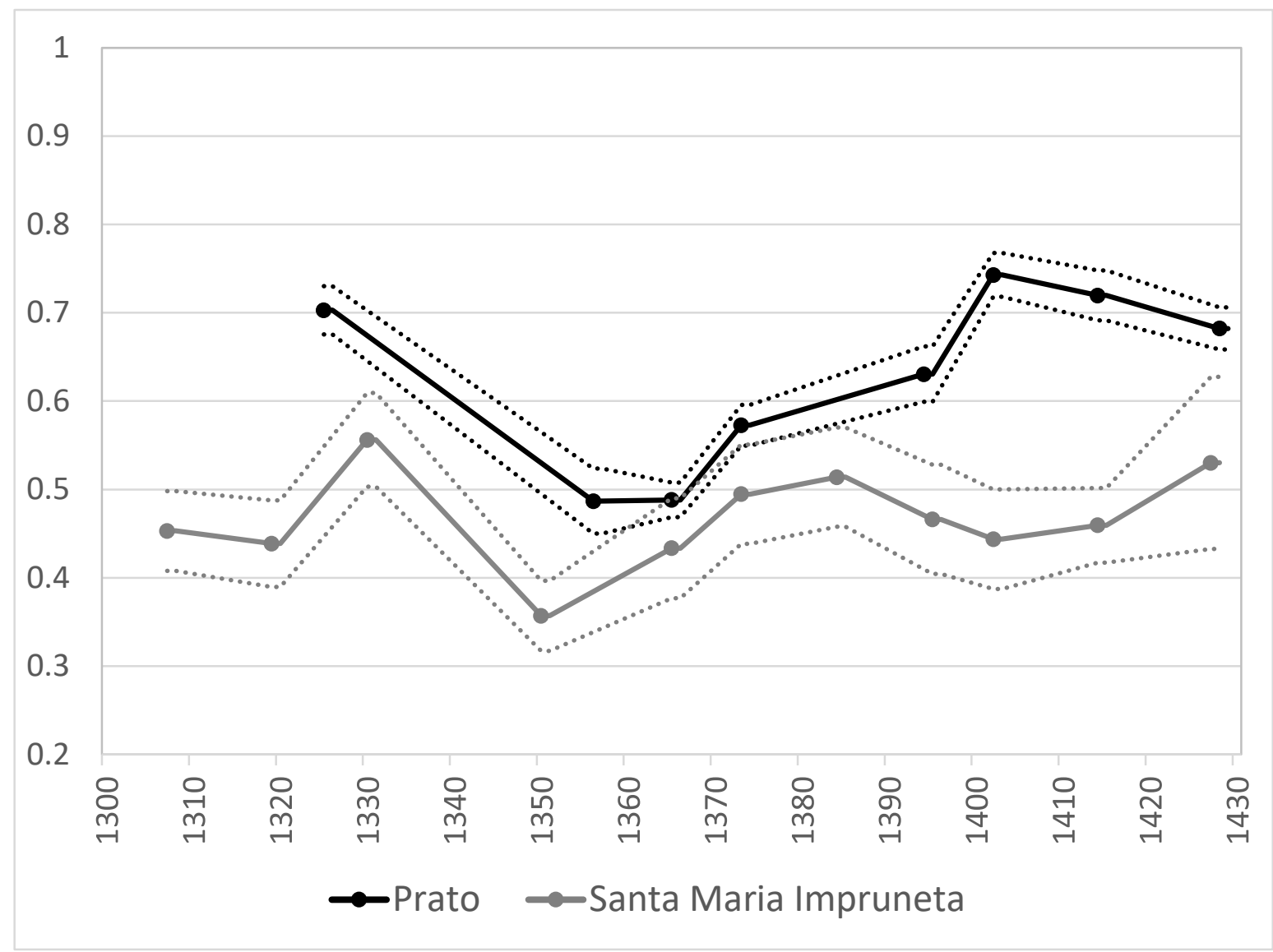

Sources: new elaborations based on data from Alfani and Ammannati 2017 and Alfani, Ammannati and Balbo 2020.

In Prato, the Gini index of wealth inequality fell from the high level of 0.703 found for 1325 to just 0.487 in 1356, a relatively very low level around which it remained for a couple of decades. Inequality growth resumed from the $1370 \mathrm{~s}$, and by 1394 the Gini index had grown to 0.630. At the beginning of the fifteenth century it had even exceeded the pre-Black Death level (peaking at 0.743 in 1402) but during the fifteenth century it tended to stabilize around a level that remained lower than that found before the pandemic (Alfani and Ammannati 2017). A similar tendency is found in Santa Maria Impruneta, where inequality was overall on the rise in the first decades of the fourteenth century, reached an observed peak of 0.556 in 1330 , then fell by one third, to just 0.357 , by 1350 . As in Prato, also in Santa Maria Impruneta inequality growth resumed from the last 
decades of the fourteenth century, but here the pre-Black Death levels were not to be seen again, not even temporarily, before the eighteenth century.

In both communities, as in most other cases that we have available for Tuscany, the drop in inequality levels between the closest pre- and post-pandemic observations was dramatic: a contraction in the Gini index of $30 \%$ or more means, in actual distributive terms, a radical upturning of the original situation. This being said, Tuscany, and more particularly the Florentine State to which the above-mentioned communities belonged, stands out among the Italian regions for which we have usable information as the one where a tendency towards inequality growth resumed earlier. In Piedmont in northwestern Italy, the overall tendency was for a marked drop in wealth inequality immediately after the Black Death, followed however by a tendency towards a further reduction in inequality that continued until the mid-fifteenth century. Only after that moment would inequality decline be replaced by a monotonic tendency towards inequality growth that continued until 1800 at least (Alfani 2015).

These findings for Tuscany and Piedmont seem confirmed by provisional results from other Italian regions (Marches and Romagna) and from other European areas. Across southern Europe and also in parts of central Europe sources entirely analogous to the Italian estimi exist, which ensures a high degree of comparability. For France, we have the important city of Toulouse, where the Gini index of wealth inequality declined from 0.752 in 1335 to 0.606 in 1398 (Alfani 2020a). In another southern French city, Albi, a post-pandemic reduction in inequality is also to be found, although of much more limited import (from 0.637 in 1343 to 0.628 in 1357). In the territory of Valencia in northeastern Spain, a tendency towards a decline in wealth inequality has been reported for Castelló between 1398 and 1468, with a Gini index of 0.54 and 0.49 respectively, and has been described as the consequence of the Black Death (Furió et al. 2020, pp. 181 and 185). This tendency, very similar to that found for Piedmont (in Castelló inequality growth resumed after 1468), has also been found by a recent systematic study of long-run inequality trends in preindustrial Germany. There, not only did the Black Death cause a sudden drop in wealth inequality levels, but it also started a phase of inequality reduction that continued for about a century: "In the post plague decades, inequality as measured by the Gini index decreased continuously [...]: in Esslingen from 0.755 around 1350, to 0.657 in 1400, and to 0.627 in 1450; 
in München from around 0.747 in 1350 to 0.659 in 1400 and then to 0.605 in 1450; in Frankfurt from 0.766 around 1350 to 0.719 in 1400" (Alfani, Gierok and Schaff 2020, p. 14).

While the relatively abundant evidence we now have for wealth distribution strongly supports the view that the Black Death triggered a phase of inequality reduction, for income inequality we have less information and the available estimates tend to be more tentative and somewhat indirect. For England as a whole, a recent study based on a set of social tables estimated a Gini index of income inequality of 0.33 for 1290, which basically remained the same by the next observation, in 1381 (Broadberry et al. 2015). This, however, with two caveats: first, the 1381 social table is described by its authors as "provisional", secondly, for 1290 an earlier estimate exists that would place income inequality at 0.367 (Milanovic, Lindert and Williamson 2011), so quite higher than the value reported for 1381, implying inequality decline in-between presumably attributable to the Black Death. Also note that a still-provisional study of English wealth inequality suggests an increase between 1327-32 and 1524-25, but at the same time argues for a very probably unobserved "U-path" in-between, caused by the plague, based on similitudes between the patterns shown by other observed variables, like real wages, in England and in continental Europe (Alfani and García Montero 2020).

In continental Europe, a tendency towards declining income inequality has been reported for the city of Bruges in the Low Countries from the second half of the fourteenth to the fifteenth century (growing inequality resumed thereafter. Ryckbosch 2016), which again fits well the pattern described above for wealth inequality. Spain might have been an exception, due to initial conditions very different from those prevailing in most of western Europe, at least in the immediate post-Black Death years (significant income inequality decline is found also in this area from the 1370s until the mid-fifteenth century. Álvarez Nogal and Prados de la Escosura 2013, with further refinements in Prados de la Escosura, Álvarez Nogal and Santiago-Caballero 2020).

Although estimates of income inequality before and after the Black Death remain very rare and mostly quite tentative, the view that income inequality declined after the pandemic finds stronger support in information of another kind: the reported trends in real wages of unskilled labourers, that can be reconstructed based on relatively solid archival information. While this information is no substitute for a direct analysis of the income distribution, nevertheless in the context of preindustrial societies it can be expected to proxy quite well the general tendencies in inequality 
change when comparing periods immediately preceding or following a large-scale mortality crisis. In this specific context, income inequality tended to decline when real wages of unskilled workers increased, and vice versa, as this altered the ratio between average incomes and incomes of unskilled workers. ${ }^{4}$ Moreover, "in view of the importance of demographic cycles in the determination of wages and the distribution of income [during the Middle Ages] [...], it is most likely that [this ratio] also varied over the demographic cycle depending upon the extent of the labor shortages. We expect that the ratio of incomes derived from skilled labor, land, and capital to the average unskilled wage was higher during periods when population was relatively high and wages relatively low [...].” (Pamuk and Schatzmiller 2014, pp. 219-220).

A condition of high population density and low real wages of unskilled labourers (and also, if the above argument holds, larger skilled-to-unskilled wage ratios) is typical of most European areas before the Black Death, while one of low population density and high real wages (and lower skilled-to-unskilled wage ratios) followed it (Pamuk 2007; Alfani and Murphy 2017; Fochesato 2018). The same might have been true for a previous major pandemic, Justinian's Plague of 54041. In Egypt, where Justinian's Plague was particularly severe having killed about half the population, there are signs of a steep and persistent increase in real wages - at least if we can interpret in such a way the increase by two and a half time of daily wages (in $\mathrm{kg}$ of wheat) of unskilled urban workers reported between year 400 and 720 (Pamuk and Schatzmiller 2014). From a high point reached in the second half of the eighth century, wages of unskilled labourers tended to decline until the early fourteenth century, a path also found in Baghdad which consequently might have experienced a similar increase in wages of unskilled labourers (and presumably, a similar decline in inequality) after Justinian's Plague. As shown in Figure 2, in Cairo a new spike in real wages was created by the Black Death of 1347-52, similarly to what is known to have happened in other parts of the Mediterranean and of Europe.

\footnotetext{
4 "The purchasing power of the wages of unskilled urban workers in terms of the bare-bones basket reflects the average purchasing power for those segments of the population whose incomes were derived from unskilled labor. However, due to the presence of higher income groups whose incomes are derived from skilled labor as well as ownership or control of land and capital, average incomes for the economy as a whole were higher than the average incomes of unskilled urban and landless agricultural workers. Recent data gathered on inequality in preindustrial societies suggest that average incomes were usually 1.5 to 2 times the wages of landless agricultural workers [...]. We should expect that the ratio of average incomes or GDP per capita to the urban unskilled wage or $\mathrm{k}$ for short would vary in preindustrial economies within a similar range [...].” (Pamuk and Schatzmiller 2014, pp. 219-220).
} 
Figure 2. Daily wages of unskilled urban workers in Cairo and Baghdad, 200-1500 (in kg of wheat)

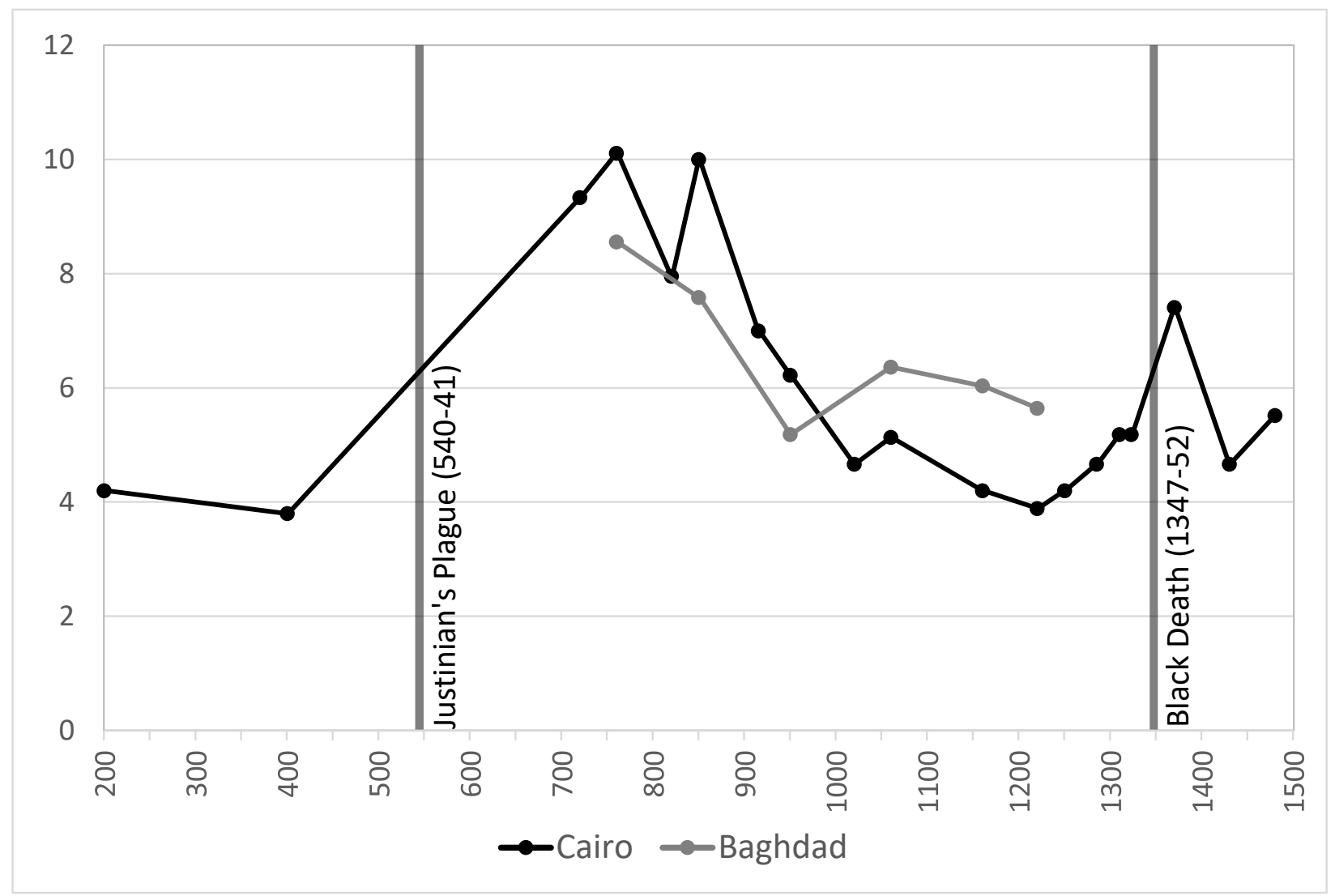

Source: elaboration based on data from Pamuk and Schatzmiller 2016

\subsection{Understanding the mechanisms of pandemic-driven inequality reduction: labour markets and institutions}

Beyond being a tentative indicator of inequality decline in the immediate post-pandemic period, increases in real wages are a crucial component of the explanation of why such decline occurred. In the aftermath of the Black Death, "A reduction in income inequality is indeed what we should expect given that for a long period labour became scarce, leading real wages to increase and to a re-balancing of labour and capital income. [...T]here is also evidence that severe labour shortages 
led to a reduction in the skill premium [...]. Consequently, labour income itself came to be more evenly distributed." (Alfani 2020a).

Higher real wages for unskilled workers also help to explain the observed reduction in wealth inequality: for a few years after the Black Death the combination of higher labour income and more properties (lands and houses) being offered for sale created a kind of "buyers' market". This allowed larger strata of the population to gain access to property, sometimes for the first time. In a sort of positive feedback loop, a more even distribution of land also led to a more even distribution of capital income -and of total income as well-, hence to greater space for leveling in the wealth distribution by reinvestment of savings, etc. In the case of wealth inequality, however, a crucial role was played by the institutional framework and in particular by the rules and practices related to inheritance. Many have argued that the degree of inheritability of (various components of) wealth is a crucial determinant of the inequality level reached by human societies in the long run (Borgerhoff Mulder et al. 2009; Bowles, Smith and Borgerhoff Mulder 2010; Piketty 2014). But in the short run, that is in the exceptional and unprecedented situation determined by the return of plague to Europe in the mid-fourteenth century, what mattered was that given the partible inheritance systems that were then prevalent across the continent, the pandemic automatically led to sudden patrimonial fragmentation (because properties had to be divided evenly among many inheritors) and also led many people to inherit land or other property that they could not, or would not, work or maintain. This led to buyer-friendly conditions in the land and housing market, as mentioned above (Alfani 2010; 2015; Alfani and Ammannati 2017).

A more detailed analysis of the distributive dynamics characterizing the immediate post-Black Death decades is offered elsewhere (Alfani 2020a). Here, it must be underlined that inequality reduction after the Black Death seems to fit quite well what we could expect based on standard Malthusian logic. To clarify this, and following the approach proposed by Williamson (2010) to make some hypothetical assumptions about the redistributive effects of the epidemics-induced demographic collapse in post-Conquest Latin America, consider the following simple model.

Let us assume that in the context of a preindustrial, mostly agrarian economy only land (R) and labour (L) matter. Given that we focus on the immediate effects of lethal epidemics and that the rate of technological change in preindustrial times was very slow, we can assume constant 
technology (A) and constant returns to scale. Consequently the total product of the economy (Y) is determined as:

$$
Y=A R^{\alpha} L^{\beta}, \text { with } \alpha+\beta=1
$$

In per-capita terms $(y=Y / L)$,

$$
\mathrm{y}=A(R / L)^{\alpha}
$$

based on this we can calculate the marginal product of land (r) and labour (w), which are respectively:

$$
\begin{aligned}
& \frac{d Y}{d R}=\alpha\left(\frac{Y}{R}\right)=r \\
& \frac{d Y}{d L}=\beta\left(\frac{Y}{L}\right)=w
\end{aligned}
$$

For a preindustrial economy, it is reasonable to assume that changes in the land rent-wage ratio $(\mathrm{r} / \mathrm{w})$ describe correctly at least the trend in overall income inequality, and this measure has been frequently used for such a purpose (beyond Williamson 2010, see for example Álvarez Nogal and Prados de la Escosura 2013). The reason for this is that "land is less evenly distributed than raw labour, so the former would capture the returns of the relatively wealthy and the latter of those less privileged" (Álvarez Nogal and Prados de la Escosura 2013, p. 12).

Based on equations (3) and (4), the land rent-wage ratio can be expressed as:

$$
\text { (5) } \quad \frac{r}{w}=\frac{\alpha}{\beta} \frac{L}{R}
$$

So, under the assumptions above and remembering that this model is proposed to understand shortterm dynamics only (the immediate post-pandemic years, maybe up to a few decades), inequality (measured as r/w) will tend to drop after a shock to labour (L) of the kind caused by a lethal pandemic. Some studies argued that this is precisely what happened to r/w after the Black Death. More generally, this conclusion is in line with models of the preindustrial economy inspired by Malthusian dynamics, including Unified Growth Theory (Galor and Weil 2000; Galor 2011). An interesting example is the model developed by Clark (2016) specifically to analyse the economic 
consequences of the demographic catastrophe caused by the Black Death in England, as it forecasts a strong drop in the land rend-wage ratio under all but the most unrealistic assumptions about the elasticity of substitution between land, labour and capital. Some scholars have also argued that a positive relationship between population and inequality holds in the long run as well, but this is very doubtful based on the available evidence, as discussed in detail elsewhere (Alfani 2020a). What is more, as will be seen the predictions of this simple model are not always confirmed even in the short run, as the distributive outcome of a lethal epidemic depends heavily upon factors that the model does not consider.

\subsection{Generalizations and exceptions}

Although the historical experience of the Black Death might have been quite unique, it has featured prominently in recent generalizations about overall inequality dynamics in the long run of history. For example Milanovic (2016), based on some of the previously-discussed data, has argued that the Black Death triggered one of a series of "Kuznets waves" in inequality detectable throughout history. Note that in the specific case of the wave associated with the Black Death, its only kuznetsian feature would be its shape - rising inequality before the pandemic and inequality decline thereafter make for a perfect inverted $U$ path - while the mechanisms behind distributional change are, in this case, entirely different from those that, for Kuznets (1955), were associated with industrial transitions. This point is openly admitted by Milanovic: "while ups and downs in inequality did occur during the period before the Industrial Revolution, they cannot be interpreted as having been driven by rising or declining income, or, to stay closer to Kuznets's original formulation, by the 'structural' laws of motion" (Milanovic 2016, pp. 61-62). Consequently, while arguing for a cyclical trend in (income and wealth) inequality in the long run of history ${ }^{5}$, Milanovic does not provide us with a single explanation of its drivers. According to him, in preindustrial times "Wages and inequality were driven up or down by idiosyncratic events" (Milanovic 2016,

\footnotetext{
${ }^{5}$ Note that a possible criticism of Milanovic's hypothesis that inequality in human societies has a cyclical nature is that it does not account for the underlying upward trend reported by a growing body of research: "Between catastrophes, the tendency was almost invariably for inequality to grow, as per inertia. Hence, waves notwithstanding, the underlying inequality trend was oriented upwards: which is something that Milanovic did not detect, but which is possibly the most important historical development we have to explain." (Alfani 2020a).
} 
p. 50), severe epidemics and pandemics included, and consequently, at least on principle, each episode of sudden distributive change could have singular and very specific causes.

Stronger assumptions about the factors able to produce large-scale fluctuations in preindustrial inequality have been made by Scheidel (2017). The Black Death, then, would simply be an example of the ability of large-scale catastrophes to forcefully impose a more egalitarian distribution of income and economic assets - indeed, Scheidel sees violence as a necessary prerequisite for inequality decline. For him, only large-scale violence could be expected to deeply disrupt the pre-existing equilibria, including the political and power equilibria which in normal instances determined the concentration of coercive force, considered itself a crucial determinant of the concentration of economic resources 6 . From the point of view of its "leveling power", then, large-scale and lethal pandemics would be on a par with events like World Wars, or the final collapse on the Roman Empire. In the specific case of the Black Death in England,

"The underlying logic is clear. A reduction in the price of land and food and a rise in the price of labour were bound to favour the poor over the rich and thus were likely to attenuate both wealth and income inequality. [...] [A] new law of 1363 permitted everyone except the lowliest manual labourers to wear furs. The authorities merely sought to ordain which animal skins could be worn by members of which social group, from rabbit and cat at the bottom end of the social order to white muscalid furs at the top. It was a sign of growing mass affluence and eroding status barriers that even those more modest restrictions came to be disregarded. And whereas ordinary mortals were now in a position to afford what used to be elite prerogatives, the nobility faced crisis as the value of the agricultural products of their estates dropped and the wages of those who made them rose. [...] Land incomes for English rentiers fell by 20 to 30 percent in the first half of the fifteenth century alone. Members of the gentry suffered downward mobility, whereas great lords managed to maintain their standing on reduced income. The plague contributed to a dramatic contraction of the nobility: over two generations, three quarters of noble families were left without heirs [...] Elite ranks shrank in size and fortune [...].”

There is little doubt, based on the available historical evidence, that Scheidel is right about the fact that large-scale catastrophes can easily result in large-scale inequality reduction. For the period of

\footnotetext{
6 "Political inequality reinforced and amplified economic inequality. For most of the agrarian period, the state enriched the few at the expense of the many: gains from pay and benefactions for public service often paled next to those from corruption, extortion and plunder" (Scheidel 2017, p. 5).
} 
the World Wars, this was mostly the consequence of the destruction of physical and financial capital, which reduced wealth and (total) income inequalities as strongly argued by Piketty (2014). But at the time of the Black Death and of all other major lethal epidemics of the preindustrial times, catastrophe affected human capital -in terms of the loss of life and of competences- and only marginally physical or financial capital. Because of this, the outcome of these events tends to depend much more on institutions, as shaped in time by human agency, than is the case for other catastrophes of the kind that caused large-scale material destruction (as with major wars) and/or led to institutional collapse (as with the crumbling of the Roman Empire in Europe and the Mediterranean and the Tang Empire in China). This is the reason why Scheidel, and Milanovic as well, while they provide us with a useful analysis of how a major pandemic happening in a preindustrial setting can reduce inequality, fail to observe (and consequently do not really try to explain) that only very few historical pandemics did produce their supposed leveling effects ${ }^{7}$.

In the case of the Black Death, the evidence is overwhelmingly in favour of a significant and longlasting pandemic-induced reduction in inequality. As seen above, Justinian's Plague might be another example of an inequality-reducing severe plague pandemic, but in this case the available evidence remains very limited and tentative (some additional evidence is provided by Scheidel 2017, pp. 323-325). A third example might be the string of epidemics, of smallpox, typhus, measles, and others that jointly played a crucial role in causing the demographic collapse of the central and southern American societies after the arrival of the Europeans in 1492 (Livi Bacci 2006; Newson 2006). While the available figures remain contentious (Nunn and Qian 2010), it is possible that at least in some areas that were very densely populated to begin with, like Mexico, the cumulative effects of these repeated mortality crises reduced population by over $80 \%$ (see Alfani and Murphy 2017 for further discussion). As has already been mentioned, Williamson (2010) argued that, based on simple Malthusian logic, we could reasonably expect such a

\footnotetext{
${ }^{7}$ Another criticism of Scheidel, this time related to his views about an unavoidable tendency for inequality growth in the long run, has again to do with the role played by institutions: "human agency, mediated by institutional change, is even more important in shaping inequality trends (both upwards and downwards) in the very long run of history than Scheidel presumes, and institutions do not necessarily reflect the interests of rapacious economic elites, but can also be designed in a way that protects the general population from excessive greed. Historically, fiscal systems seem to have played a particularly important role. [...] The lull and even further decline in inequality after the end of World War II was the effect of human agency and institutions, and particularly of the redistributive policies and the development of the welfare states from the 1950s to the early 1970s. These examples suggest that human agency the explicit, intentional attempts of human beings to change things - could have an impact on inequality trends, either reinforcing inequality growth or even, at least in relatively recent times, inverting what seems to be a somewhat spontaneous tendency for income and wealth to become ever more concentrated." (Alfani 2020a).
} 
catastrophe to lead to some inequality reduction. Evidence supporting this view has been provided by a recently-published series of real wages in central Mexico, that shows the growing pattern that we can expect to be associated with declining (income) inequality as a string of severe epidemics unfolds (Arroyo Abad, Davies and Van Zanden 2012). However, growing real wages are reported only from the early seventeenth century, when the labour market experienced a degree of liberalization. In the sixteenth century, real wages remained stagnant in spite of frequent epidemics, a circumstance also noted by Scheidel: "The answer [to this apparent puzzle] probably lies in Spanish reliance on coercion to secure labor in the face of demographic contraction, a practice rooted in pre-Columbian regimes of forced labor. Government intervention may consequently have suppressed wage bargaining for an extended period of time" (Scheidel 2017, p. 318. On this point, also see Williamson 2010, pp. 242-243).

Scheidel's observation about the role played by institutions, which might have effectively avoided increases in real wages in sixteenth-century Mexico and at the same time probably prevented any substantial reduction in inequality, should serve as a reminder that we can't really predict distributive dynamics based solely on demographic developments. But if this is true, then more generally we should expect that post-pandemic inequality decline will not simply be a function of the associated mortality rates. As a matter of fact, not even the Black Death seems to have had homogeneous consequences across the affected areas. In Europe, for example, we know that the overall positive long-term effects of that pandemic were enjoyed by most, but not all, of the continent. In geographically peripheral areas like Ireland or Spain, which were relatively underpopulated to begin with, the long-term economic consequences of the Black Death were negative, not positive (Alfani and Murphy 2017; Alfani 2020c). In Spain, for which we have some in-depth studies, the pandemic ended almost a century of quick growth: "In pre-plague Spain, Malthusian forces were mostly absent except for a few, if any, areas along the Mediterranean coast. Sustained progress took place after the Reconquest in the context of a frontier economy, urban expansion, and openness to trade. Although its death toll was lower, the plague had a much more damaging impact in Spain than in Western Europe since, far from releasing non-existent demographic pressure on land, it destroyed the equilibrium between scarce population and abundant resources. Pre-Black Death per capita income levels were temporarily recovered by the late sixteenth century, but were only exceeded after 1820" (Álvarez Nogal and Prados de la Escosura, 2013, p. 3). 
The case of Spain stands out, when compared to other European areas, also because it did not enjoy a reduction in income inequality after the Black Death. This view is supported by two different measures of income inequality: the land rent-wage rate ratio (introduced previously) and the Williamson index ${ }^{8}$. Both measures suggest that income inequality grew during the four decades or so immediately following the Black Death, as can be seen in Figure 3 for the Williamson Index (Álvarez Nogal and Prados de la Escosura 2013, with further refinements in Prados de la Escosura, Álvarez Nogal and Santiago-Caballero 2020). The figure, however, also shows that a phase of income inequality decline started from the late fourteenth century and continued until ca. 1430, after which inequality growth resumed. This helps to reconcile the trend in income inequality with the previously-commented estimates of wealth inequality that are available for the Kingdom of Valencia.

\footnotetext{
${ }^{8}$ The Williamson index in particular, introduced by Jeffrey Williamson (1997), has been described as "[a] crude inequality indicator of income distribution, [calculated as] the ratio of nominal output per capita to nominal wage rates, expressed in index form [...]. The rationale of such an indicator is that while the numerator captures returns to all factors of production per occupied person - and here we assumed that the labour force expanded at the same pace as the total population - the denominator represents the returns to raw labour, so the bottom of the distribution is compared to its average." (Álvarez Nogal and Prados de la Escosura 2013, p. 20). Note that, for the specific case of Spain, Prados de la Escosura (2008, p. 299) has shown that before 1950 the trends in the Williamson index and the Gini index of income inequality were highly correlated. For a recent application, see Beltrán Tapia and MartinezGalarraga 2020.
} 
Figure 3. Income inequality in Spain, 1300-1500 (Williamson Index of inequality, nominal values in logs)

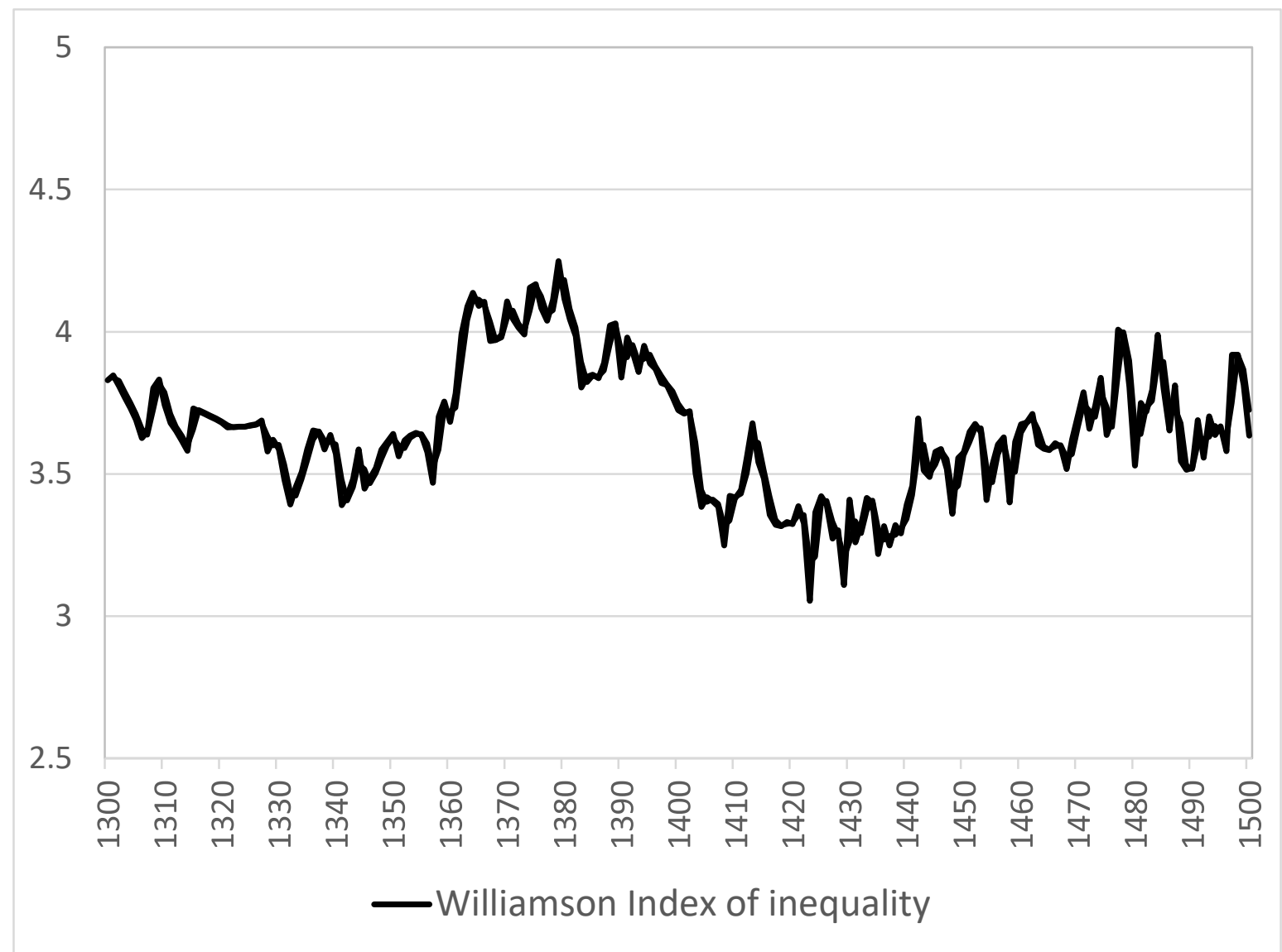

Source: elaboration based on data from Prados de la Escosura, Álvarez-Nogal and Santiago-Caballero (2020).

Both land rent-wage rate ratio and Williamson index are to be considered fairly rough and indirect indicators of inequality and strictly inferior to, say, the Gini index calculated on a complete observed distribution, hence a degree of uncertainty remains about the actual distributive dynamics of post-Black Death Spain. Research about more recent episodes has provided stronger evidence supporting the view that the way in which severe epidemics affect inequality depends strictly upon the initial conditions and the institutional framework existing at the onset of the crisis. 


\section{The redistributive impact of epidemics: from the plagues of the seventeenth century to cholera}

Some scholars have focused on the last great plagues that spread through Europe in the seventeenth century. These epidemics affected in a particularly severe way southern European areas, like Italy, southern France and Spain, as well as south Germany where however their effects (both of the demographic and the socio-economic kind) are inextricably intertwined with those of the devastating Thirty Years' War of 1618-48 (Eckert 1996). The plague wave that started probably in northern France in 1623, spread to England, France, Germany, the Low Countries and Switzerland and finally, in late 1629, entered Italy ravaging the north of the Peninsula the

following year and Tuscany in 1631 is particularly noteworthy. For southern France and northern Italy this is usually considered the worst plague among the many that followed the Black Death. In north Italy, it killed $30-35 \%$ of the overall population, causing about two million victims. Interestingly, central and south Italy were affected by another terrible plague wave, in 1656-57, which spared precisely the areas of the North (plus Tuscany) that had been infected in 1629-30 (in the Kingdom of Naples, this epidemic killed in-between 30 and $43 \%$ of the overall population) (Alfani 2013; Alfani and Murphy 2017).

\subsection{Absence (or almost) of inequality decline after the seventeenth-century plagues}

In the worst-affected areas of southern Europe, the seventeenth-century plagues were characterized by mortality rates on a level not dissimilar from those typical of the Black Death. And yet, they did not interrupt the monotonic upward trend in wealth inequality that seems to have characterized Italy and most other European areas from around the second half of the fifteenth to at least the beginning of the nineteenth century (Alfani 2017; 2020a). Here it will suffice to show the immediate pre- and post-plague observations available for a sample of five northern Italian cities. Ordered from west to east: two for the region of Piedmont (Saluzzo and Moncalieri), one for Lombardy (Bergamo) and two for Veneto (Padua and Verona). To these, the city of Cherasco in Piedmont is added: as this was the exceptional case of a northern Italian city entirely spared from plague during 1629-30, it can be used as a placebo. As seen in Figure 4, not only is there no apparent difference in the observed trends between the placebo and the cities which suffered from the plague, but even among the latter there is no clear correlation between local intensity of the 
epidemic and changes in inequality (the estimated mortality rates are 381 per thousand in Bergamo, 594 per thousand in Padua, 615 per thousand in Verona, unknown in Saluzzo and Moncalieri, and obviously zero in Cherasco which was surely spared ${ }^{9}$. Alfani and Di Tullio 2019, p. 115). The partial exception is Bergamo, where a small decline is observed (from a reported Gini of 0.723 in 1610 , to 0.715 in 1640) which was quickly recovered, and more (0.764 in 1700) - but interestingly, of the three cities for which we have information about plague mortality rates, this was the one affected less severely. These results need to be interpreted conservatively, as sample size and a varying time distance from the event to the closest post-plague observation might matter and plague intensity might have had more complex consequences for the local distribution than could easily be detected by a Gini index (see, for the case of the Republic of Venice, Alfani, Di Tullio and Fochesato 2020).

\footnotetext{
${ }^{9}$ During the plague Cherasco hosted the Savoy court, which had fled their infected capital, Turin. This is why the treaty ending the War of the Mantuan Succession (1628-31) was signed in this city, in 1631.
} 
Figure 4. Inequality in northern Italian cities, before and after the 1629-30 plague (Gini indexes of wealth inequality)

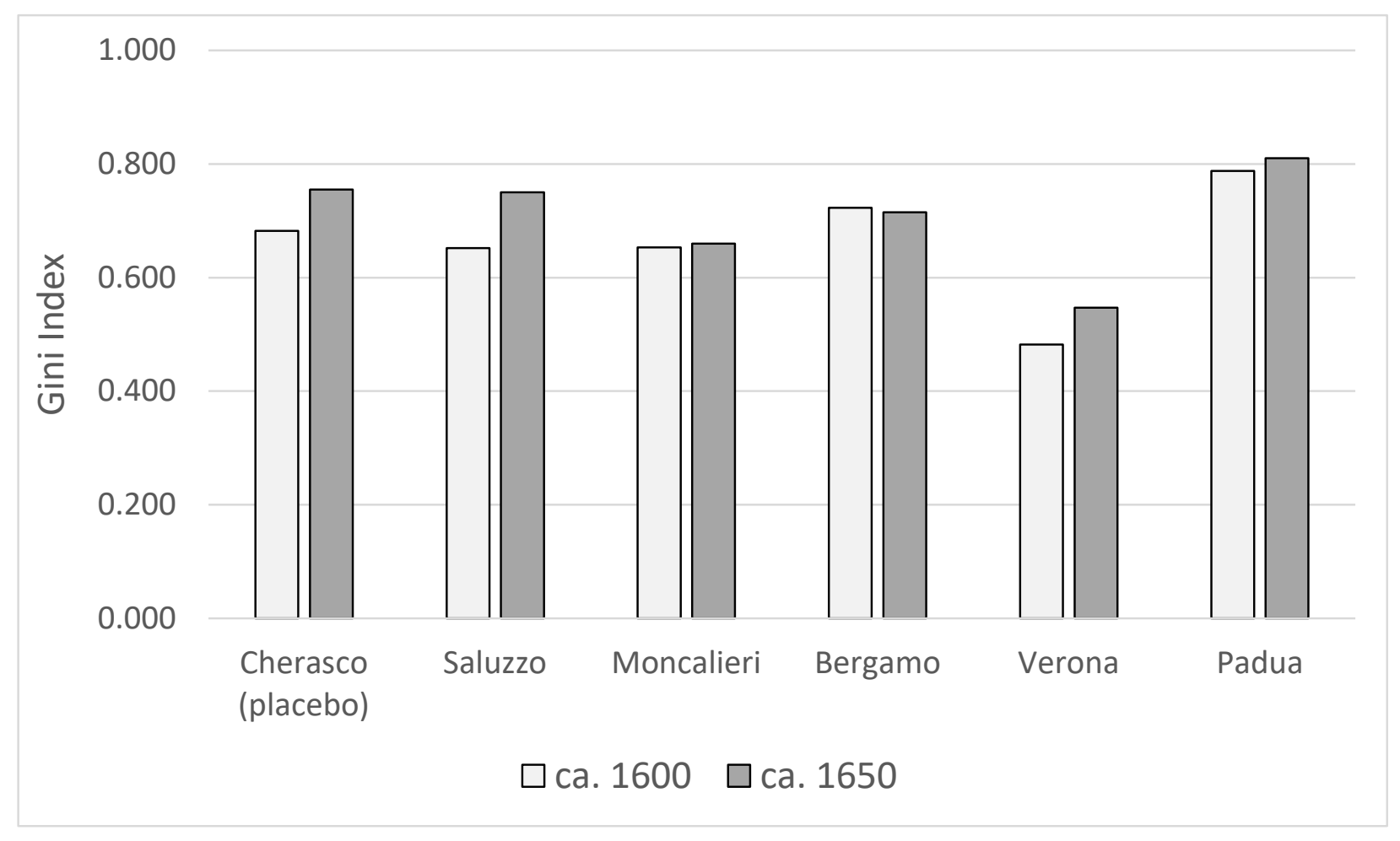

Sources: new elaboration based on data from Alfani (2015) and Alfani and Di Tullio (2019).

The fact that the seventeenth-century plagues, notwithstanding their magnitude, proved unable to cause a reduction in inequality is highly relevant for our understanding of how a severe epidemic can alter the wealth and income distribution. Why is this case so different from that of the Black Death? Some first insights come from those very few instances where we have exceptionally good opportunities (due to the survival of exceptionally good archival sources) to observe how the plague impacted the distribution in the short run, and not only in the medium or even the long run. The best such case is the city of Ivrea in northwestern Italy, for which it has been possible to reconstruct complete distributions of taxable wealth (based on the estimi as well as on rare local books of corrections to the estimi) for the period 1620-49. The related trend can be observed in Figure 5. In Ivrea, which like most Piedmontese cities was affected by the 1629-30 plague, we observe a drop in inequality concomitant with the epidemic - but the recovery was extremely 
quick, and indeed the fall of the Gini index had already been more than compensated for by 1632 (Alfani 2010).

Figure 5. Wealth inequality in Ivrea, 1620-49 (Gini indexes)

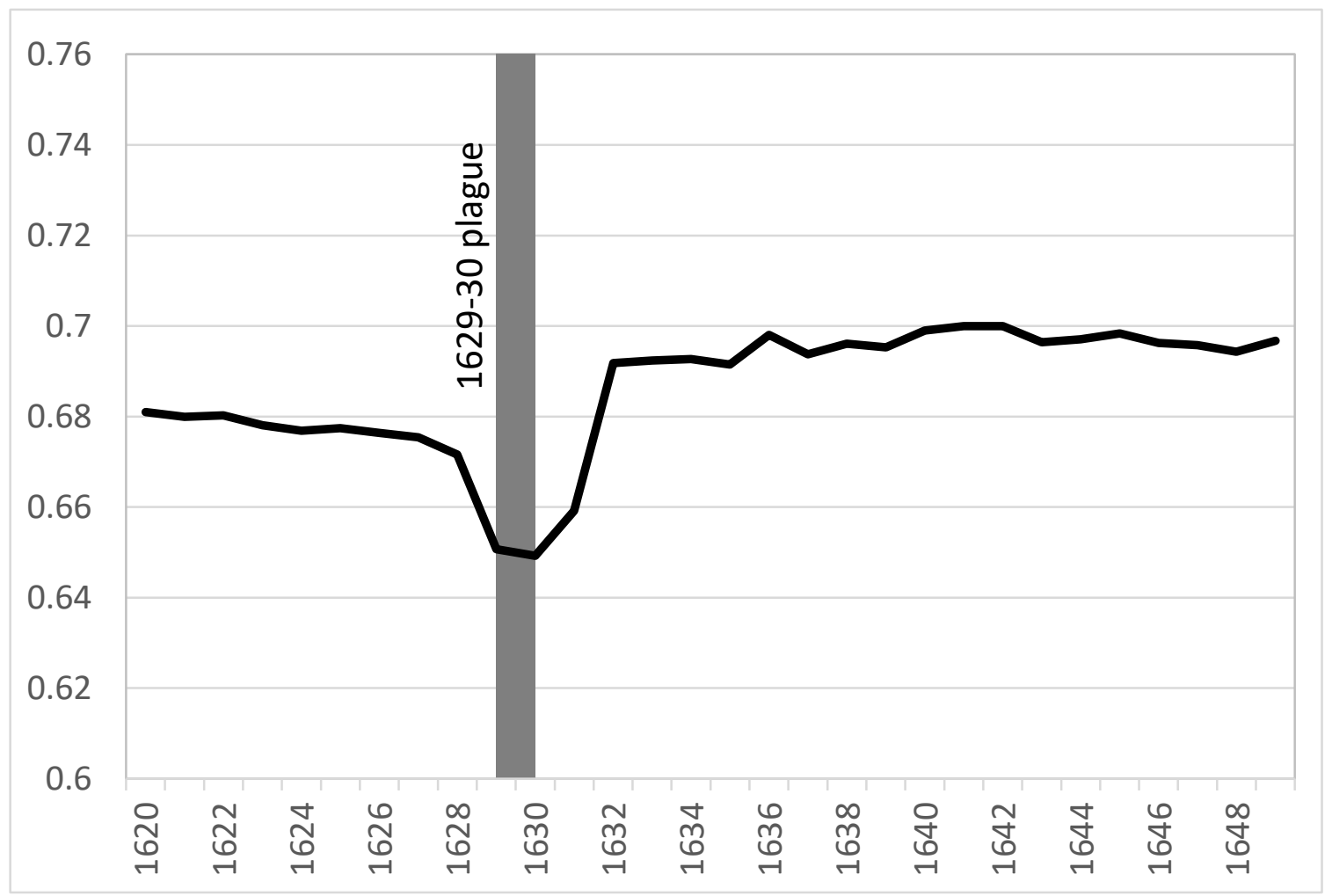

Source: new elaboration based on data from Alfani 2010.

The case of Ivrea suggests that the seventeenth-century plagues did have an impact on redistribution (and it would be technically impossible otherwise, as we are facing events that killed one third and more of the population), but that if measured at the aggregate level (for example by the Gini index, or as the share of the richest 10 or 5 percent of households) this impact turns out to be limited and extremely short-lived. So, since in most instances the surviving sources only allow us to observe the wealth distribution every few decades, it seems probable that these short-term effects were generalized - but hard to observe. And yet, given that the information available for the seventeenth century is vastly more abundant than that we have for the fourteenth, the difference 
between the Black Death and these later plagues remains dramatic: the Black Death was able to cause such a large and persistent reduction in inequality that it remains easily visible even with our poor observation instruments.

\subsection{Explaining the different outcomes after the seventeenth-century plagues and the Black Death}

Why was the plague-related inequality reduction so limited and evanescent in early modern times? Arguably the answer lies in very different initial conditions, beginning with the institutional framework. When plague came back to Europe and the Mediterranean in 1347, after having disappeared from this area many centuries earlier, European societies were not ready to face the threat. But when recurring epidemics made it clear that plague had become a stable feature of their environments, Europeans adapted -and for the human species, institutional and cultural adaptation is an essential component of their reaction to changes in the biological environment. Such adaptation also involved those institutions that have been singled out as playing a crucial role in mediating the redistributive effects of pandemics: "Although inheritance systems throughout Italy were partible before and after the Black Death, the crisis led to the spread of institutions to protect the largest patrimonies from the risk of dispersion. Fideicommissum, which guaranteed that a welldefined set of family properties were transferred unaltered from one generation to the next, is probably the most common and well known [...]. This and similar institutions made patrimonies more resilient to mortality crises, but entrenched wealth inequality." (Alfani and Murphy 2017, p. $334)$.

European societies of the seventeenth century were prepared to face the threat of plague, and none more so than the Italian ones, which had been at the forefront of the development of means to fight epidemics that are the direct forerunners of those still used today (quarantine procedures; plague isolation hospitals called lazzaretti; permanent health boards....). But being prepared also means being able to avoid the unwanted "egalitarian" effects of severe plagues, and calls into question the connection between social resilience and inequality in preindustrial societies. While some have argued that less unequal societies might prove more resilient when they have to face environmental shocks (Curtis 2014; De Keyzer 2018; and in a more nuanced way Van Bavel, Curtis and Soens 2018; Van Bavel et al. 2020), a view that also finds some support in contemporary catastrophe 
studies (Kahn 2005; Carter et al. 2007), it also seems quite probable that in the specific context of most preindustrial European societies (and maybe others having similar inheritance systems and practices), "higher societal resilience to shocks determines lower inequality decline in the immediate aftermath of the crisis - and also allows for reaching even higher inequality levels shortly afterwards, for example as a consequence of migration" (Alfani and Di Tullio 2019, p. 121). Consequently, the historical correlation between inequality and social resilience might have been positive, not negative.

Deeply mutated practices regarding inheritance of the largest patrimonies go a long way towards altering the mechanisms that have been proposed to explain how the Black Death produced its egalitarian effects. But also looking at the other crucial factor on which the literature has focused, real wages, the seventeenth century looks entirely different. If we compare the reaction of real wages to the fourteenth century Black Death and to the seventeenth-century plagues, as is done in Figure 6, a stark difference is immediately apparent. In the fourteenth century, the Black Death is associated with a phase of rapidly-growing real wages, more clearly in the centre and south of the continent than in the northwest. In the seventeenth century, plague seems to have had no positive impact on real wages, not even in southern Europe which, as has been seen, suffered for epidemic mortality on a scale not dissimilar to the Black Death. This holds true even if we look closely at relevant cases: as can be seen in part B of Figure 6, real wages did not raise in Milan after the 1630 plague had caused an estimated mortality of 462 per thousand, nor in the city of Valencia where about one third of the population died of plague in $1647-48^{10}$. Similar conclusions, for the 165657 plague in central and southern Italy, have recently been reached by Rota and Weisdorf (2020) using a new series of real wages for the city of Rome.

Based on this kind of evidence, Fochesato (2018) argued for a structural change in the way in which real wages reacted to population dynamics. This would have happened in northwestern Europe earlier than elsewhere (from the $16^{\text {th }}$ century at the very least), and this precocious escape from Malthusian constraints -an escape which supposedly allowed for improvements in living standards, and for relatively high real wages, also in times of high population density and steady population growth- would have promoted the Little Divergence between North and South. While

\footnotetext{
${ }^{10}$ See Alfani and Percoco (2019) for additional examples.
} 
this might be true if we focus on the long run ${ }^{11}$, from the point of view of the short- and mediumterm reactions to plagues and other large-scale mortality crises the issue that we have to explain is exactly the opposite: why don't we observe any kind of "Malthusian" improvement in real wages in the European South (which, Fochesato argues, in the seventeenth century was still fully subject to Malthus' laws ${ }^{12}$ ) after the death of $30-40 \%$ of the overall population had tended to make, yet again, resources abundant and labour scarce?

Figure 6. Real wages of unskilled workers, 1300-1400 and 1600-1700 compared (in grams of silver)

A. Real wages and the Black Death

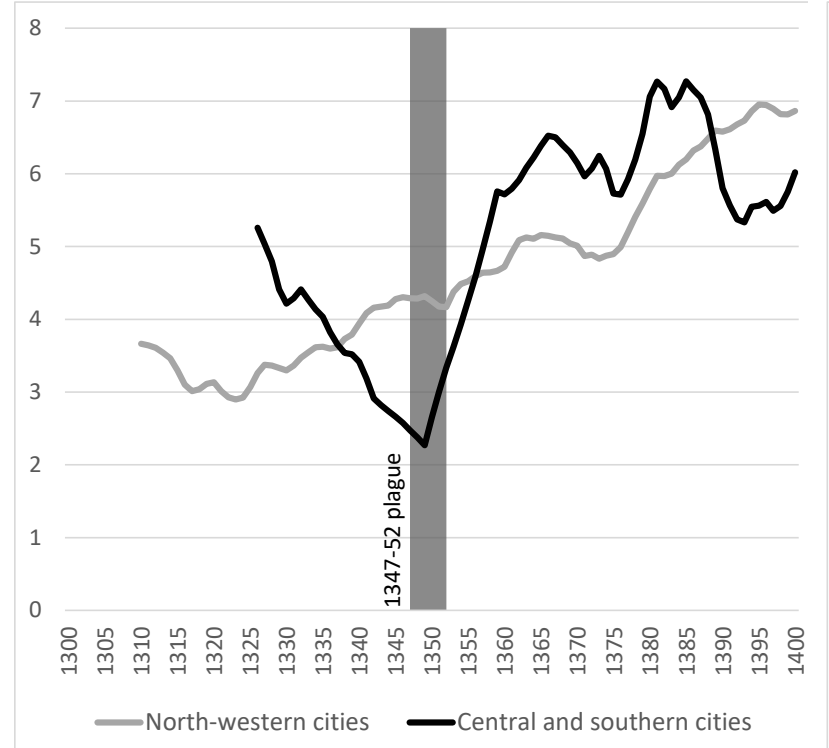

B. Real wages and the plagues of the 17 th $\mathrm{C}$.

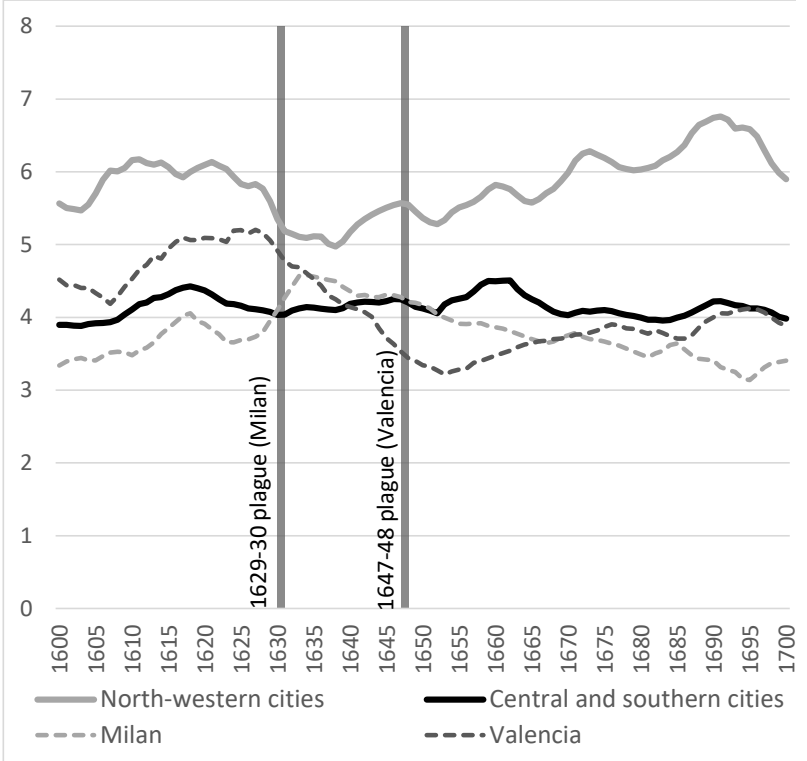

Sources: new elaboration based on data from Fochesato (2018).

To solve this apparent puzzle, and following the approach developed by Alfani and Percoco (2019), it is useful to consider how the seventeenth-century epidemics might have affected the labour market in Italy (but the same reasoning could be applied to other southern European areas which experienced similar initial conditions and were severely affected by plague). All lethal epidemics cause, as the simple result of high mortality, a contraction in the labour supply. In Figure

\footnotetext{
${ }^{11}$ Note that the timing of the Little Divergence remains debated: compare for example Van Zanden 2009; Alfani 2013; Fouquet and Broadberry 2015; Fochesato 2018.

${ }^{12}$ This view finds some support in recent studies of famine: Alfani and Ó Gráda 2018.
} 
7, this is represented by S moving to S', which tends to increase the wage of survivors from $\mathrm{w}^{*}$ to $\mathrm{w}^{*}$. This is exactly what is usually considered to have happened at the time of the Black Death, and fits well the empirical findings about increasing real wages of unskilled workers after that specific pandemic (Figure 6A). But if we allow for a plague-induced shock in labour productivity as well, then also labour demand would contract, from D to D'. In this scenario, the net impact would depend on the relative size of the two shocks, and there would be no a priori reason to expect that a severe plague led to higher real wages.

In Figure 7, two shocks of about equal size with countervailing effects keep the wage of survivors around the original value, $\mathrm{w}^{*}$, which fits well the trends observed for the seventeenth century (Figure 6B). Alfani and Percoco (2019, pp. 1181-1185) provide a series of reasons why plague might have caused a productivity shock in seventeenth century Italy. First of all, damage done by the plague to the stock of human capital and the subsequent shortage of skilled workers (note that scarce availability of skilled workers might have made it impossible to maintain high production levels for sophisticated products, leading to lower demand for unskilled workers); grievous losses among the economic elite who organized urban production; reduction in the amount of capital available for urban manufactories, because of the transfer of capital from the manufactories to investment in land and because of the transfer of part of the productive activities from the cities to rural areas, where they could escape the rigidities of the guild system. All this, in the very specific context of intense competition from northern European economies, like the Low Countries, which were keen to subtract from their Italian rivals shares of the European market for crucial products, like textiles, and were also advantaged by the new opportunities offered by the opening of the Atlantic trade routes. Indeed, circumstances contribute to explain why many members of the northern Italian economic elites were quite ready, after the shock caused by the 1629-30 plague, to divert capital from industry and trade to agrarian investments. Crucially, this happened also because, while the Black Death had a more or less even demographic impact across Europe, the seventeenth century plagues affected the south much more severely. For example, while the 162930 plague alone killed 30-35\% of the population of north Italy, all the seventeenth-century English 
plagues together caused a number of victims amounting to $8-10 \%$ of the population existing around 1600 (Alfani 2013, p. 411) $)^{13}$.

Figure 7: The possible effect of epidemic mortality on labor supply and productivity in seventeenth-century Italy

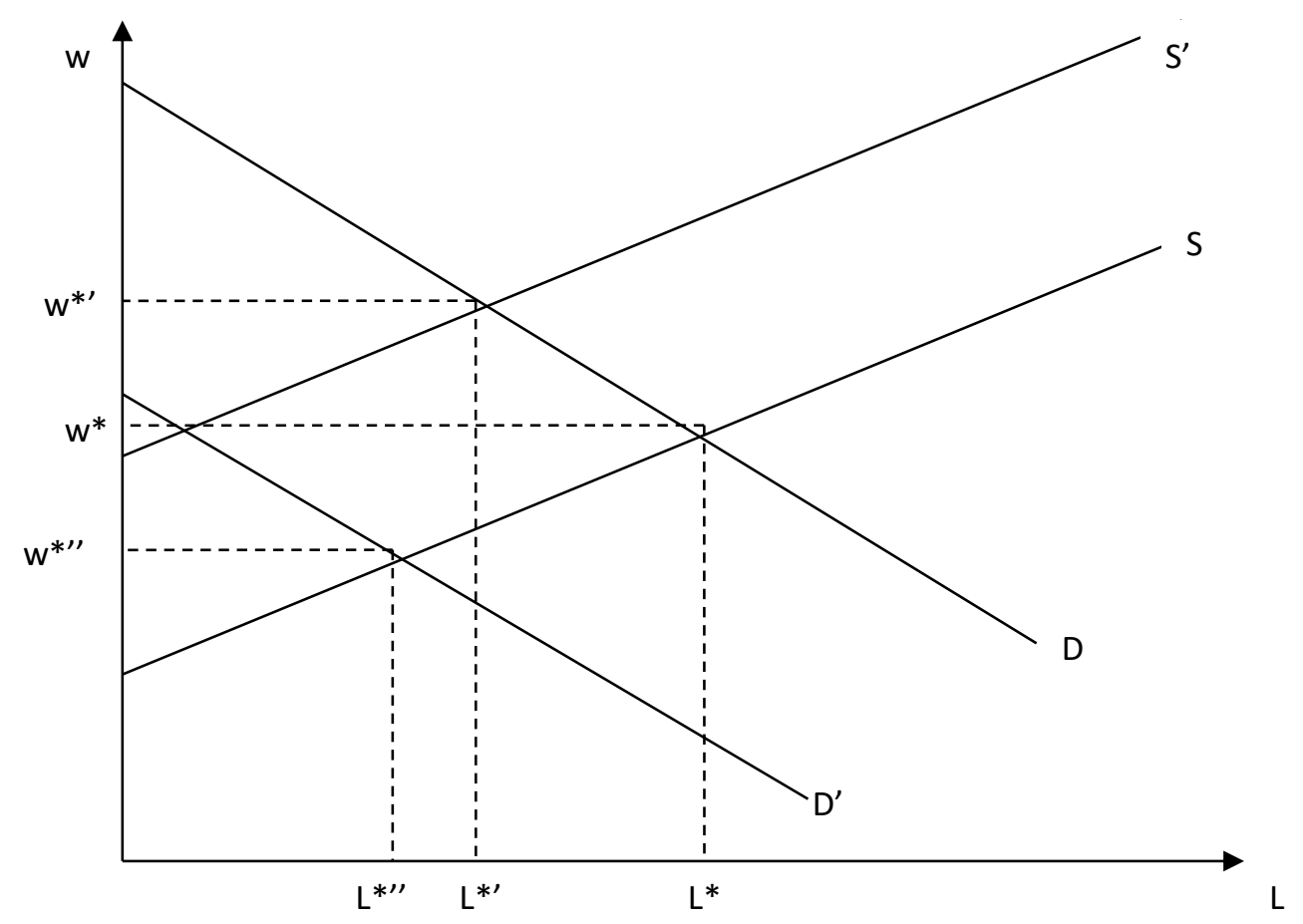

There is much, in this reconstruction, that remains hypothetical but the few available studies of the conditions of the labour market after the seventeenth century plagues do point towards a very perturbed situation (Pullan 1964), and it has been argued that also in the immediate aftermath of the Black Death human agency sometimes led to results different from those to be expected based on Malthusian logic, at least in the short run. This, for example, because of the enactment of pro-

\footnotetext{
${ }^{13}$ Note that what Alfani and Percoco (2019) referred to as a "productivity shock" affecting 1630 Italy is similar, on principle, to the "Smithian effects" postulated by Jedwab, Johnson and Koyama (2019b) to explain the long-run consequences of the Black Death on urban populations.
} 
elite labor legislation like the decrees contra laboratores ("against the labourers"), which had the objective of containing the "greed" of the lower classes. Such decrees, however, in the post-Black Death situation soon became untenable and were repealed (Cohn 2007).

The discussion so far highlights a crucial point: the outcome of a high-mortality epidemic is strictly dependent upon the conditions in which it takes place. In the case of the Black Death, the mechanism that allowed mass mortality to cause a reduction in both income and wealth inequality involved an increase in real wages, in Malthusian fashion, and was also the result of partible inheritance systems and other components of the institutional framework that were simply not ready to face a biological hazard on a scale without precedent. But when the seventeenth-century plagues struck, due to very different initial conditions they did not lead to higher real wages (a key requisite for income inequality decline) and they were mediated by institutions that, across the centuries, had adapted to the plague and now helped to avoid patrimonial fragmentation and the related decline in wealth inequality - mostly to the advantage of the economic elites.

Apart from the initial conditions, another crucial factor to take into account is how much the possible redistributive effects of an epidemic depend on the associated mortality rates. In the case of preindustrial plagues, mortality was on a huge scale and had major consequences on the labour market. But in the case of other events that are maybe able to cause a high number of victims -like the Spanish Flu of 1918-19- but through much lower mortality rates (in-between 2.5 and 5 per thousand in the case of the Spanish Flu: Johnson and Mueller 2002, p. 114), factors like the contraction of the labour force simply do not operate in the same way, and their distributive consequences are easily overcome by those of other factors. In the case of Covid-19, which is surely more similar to that of the Spanish Flu than to the Black Death, much concern has been expressed about quickly growing unemployment, especially among the poorest and most economically fragile groups, because of the pandemic itself (think about job loss for infected people or for those who will long suffer for poor health as a consequence of the infection) as well as of the containment policies (like lockdowns of various kinds) that have been applied worldwide (OECD 2020). Consequently, although caution is needed as at the time of writing the crisis is still unfolding, it seems certain that the Covid-19 pandemic will lead to higher, not lower income inequality. This view finds some support in recent studies arguing for a direct, income inequalityincreasing effect of the Spanish Flu (Galletta and Giommoni 2020). 


\subsection{Pandemics of the early industrial world: the case of cholera}

Given the relative scarcity of studies of the distributive consequences of past lethal epidemics, it seems useful to push the analysis forward and to consider, even in just a tentative way, the global pandemics caused by cholera during the nineteenth century. Interestingly, they affected a world which was already going through the industrialization process, so the context was different from that in which took place the preindustrial epidemics discussed so far - but also from the situation that already characterized much of the world when the Spanish Flu struck.

Cholera was the new disease of the nineteenth century. Its arrival in Europe was initially referred to as a "return of the plague" (Snowden 2019, pp. 234-235), also because plague had become enrooted in Western culture as the prototypical catastrophic epidemic (it remains so to this day). During the nineteenth century, cholera caused five distinct pandemics (in 1817-24, 1829-37, 184060, 1863-75 and 1881-96), with a sixth one (1899-1923) starting at the turn of the twentieth century (Bourdelais 1987; Kohn 2007). Each of these pandemics began in India, from the lower Bengal region where the infection (caused by a bacterium, the vibrio cholerae) was endemic, then spread to other areas of Asia and other continents. It is not by chance, then, that mortality was way higher in India than in any other world area. At the peak of the first pandemic, during 1817-21, it is considered reasonable to estimate 1.25 million deaths per year (Harrison 2020, p. 512). By the end of the pandemic in 1860, the overall number of deaths in India had probably exceeded 15 million, and more than 20 million others seem to have died by the end of the sixth pandemic (Arnold 1993), although much uncertainty remains about the actual figures.

Even if mortality rates were much higher in India than anywhere else (on the order of a few percentage points of the entire population per pandemic), for this country we do not have the information about inequality trends necessary to check whether such events had a detectable distributive impact. For this, we have to turn again to the West. Cholera pandemics are the first whose spread was facilitated by new means of transportation: the train and, later on, the steamship. These would make it increasingly simple for the original outbreaks in India to spread globally. Western countries were spared from the first pandemic, but were affected, to various degree, by all others taking place in the nineteenth century. In Europe, the second, third and fourth pandemics 
had particularly serious consequences. The level of mortality, while much lower than in India and some other world areas, was still considerable. In England and Wales, 21,800 people died of cholera in 1831, 53,292 in 1848-49, 20,099 in 1853-54, and 14,378 in 1866 (Ashworth Underwood 1947, p. 173). Losses were higher in continental Europe. In Italy for example, during the nineteenth century cholera caused in-between 500,000 and 700,000 victims, with the worst episode being the outbreak of 1865-67 which caused over 160,000 (Alfani and Melegaro 2010, pp. 59-60). Also France was badly hit by cholera, especially in 1832 (102,000 victims) and in 1853-54 (143,000). Cholera, however, did not spread evenly across France, but affected certain areas, and especially those closer to Paris, much more severely than others. In 1854 for example, local mortality rates ranged from 23.5 per thousand in the Seine département, to just $1.7 \%$ in the Hérault (Bourdelais, Demonet and Raulot 1978).

Figure 8. Wealth inequality and cholera pandemics in France, 1800-1910 (share of the richest $10 \%)$

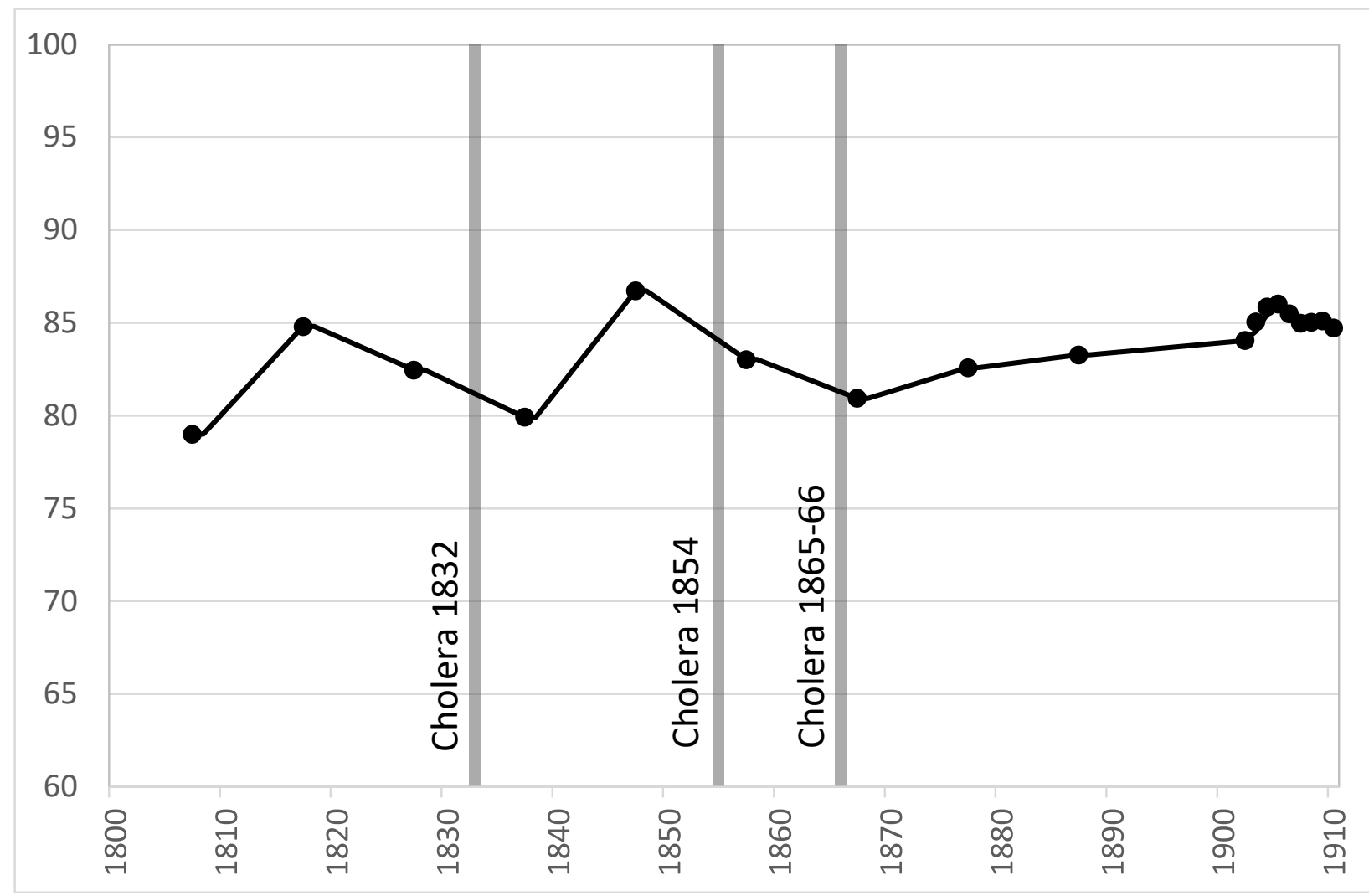

Source: elaboration based on data from WID (World Wealth and Income Database). 
France is probably the country in the world for which we have the best and most frequent information about wealth inequality during the nineteenth century (Piketty, Postel-Vinay and Rosenthal 2006; 2014; Piketty 2014). In Figure 8, the available information about the wealth share of the top $10 \%$ is shown and the cholera years are highlighted. Overall, the figure shows a stability in inequality levels, with maybe an underlying tendency towards a slow growth throughout the century (the richest $10 \%$ owned $85 \%$ of the overall wealth in 1910, up by 5 to 6 percentage points compared to the beginning of the century). But if we look at the in-between oscillations, the two main cholera outbreaks in France (in 1832 and 1854) are placed in correspondence of phases of inequality decline. However, these data have to be interpreted very conservatively, as unfortunately for most of the period we have only one observation every ten years, starting in $1807^{14}$. So, while it might be that the cholera epidemics favoured (temporary) inequality reductions in nineteenth-century France, their greatest contribution to our discussion lies in focusing our attention on the fact that this infection, which is well-known to affect the poorest groups much worse than all other strata, can be expected to have produced its main distributive effects precisely through the way in which it affected the poor. But, as seen in the next section, a poverty-related reduction in inequality can be obtained in two radically different (but not mutually exclusive) ways: a reduction in the intensity of poverty, or the extermination of the poor.

\section{Epidemics and poverty}

Epidemics differ widely in terms of the kind of households or individuals who are affected the most. When we want to make sense of their redistributive effects, a crucial factor to consider is their selectivity by social-economic status. But, given the data-imposed limitations that we face when analyzing preindustrial and early industrial pandemics, this general question can be effectively transformed into a narrower one: how did epidemics affect the poorest strata of the population?

\subsection{Selective mortality by socio-economic status}

The fourteenth-century Black Death is usually considered the best example of a mortality crisis that cuts across all social groups, without discriminating between rich and poor. Recent work based

\footnotetext{
${ }^{14}$ Ongoing research by Rosenthal (2020) seems to confirm that the 1832 cholera epidemic reduced wealth inequality in France.
} 
on skeletal sources provided evidence that this pandemic was selective with respect to pre-existing health conditions (frailty) (DeWitte and Wood 2008), but such conditions depended on age much more than on social-economic status. This being said, many studies of plague have reported that, from the fifteenth century, plague tended to increasingly focus on the poor (Slack 1985; Cohn 2010; Alfani and Murphy 2017, p. 324). Recent research on specific plague outbreaks provided evidence supporting this view (Galanaud, Galanaud and Giraudoux 2015; Whittles and Didelot 2016), which is also indirectly confirmed by Cummins (2017) who, based on the age at death of nobles, argued that overall in the period 1348-1700 plague killed this component of the elite at lower rates compared to the general population.

Although by the seventeenth century plague had acquired a socially-selective character, it is also clear that in the case of the worst outbreaks large parts of the elites were eliminated as well. For example in Genoa in 1656-57, plague killed $40 \%$ of the members of the Great and Low Councils, while in Venice in 1630 victims among the members of the Great Council were close to 20\% (Pullan 1992, p. 111). The fact that the last great European plagues were able to affect the rich as well as the poor does not mean that they did not select - they surely did, for example because of differences in the environment of residence of rich and poor. Using data about a string of plagues in London from 1560 to 1665, Cummins et al. (2016) have shown that the outbreaks usually started in the poorest part of the cities and that the residents of the richest parishes, who enjoyed better housing and overall living conditions, were less likely to die of plague. Similar conclusions have been reached for Dijon in 1400 and 1428 (Galanaud, Galanaud and Giraudoux 2015) and for Milan in 1523 (Cohn and Alfani 2007). Finally, a detailed study of the town of Nonantola in northern Italy during the 1630 plague, based on survival analysis techniques, identified a strong positive correlation (controlling for a range of other factors) between size of the group of co-residents and risk of death (Alfani and Bonetti 2019). As the poor tended to live in overcrowded houses, this might be indicative of their somewhat disadvantaged situation in the face of the epidemic.

In the case of cholera the connection between poverty and mortality, mediated by the living environment, is even clearer. As is well known, a turning point in the fight against cholera was the realization by doctor John Snow, during the 1854 cholera outbreak in London, that the infection spread more easily among those using drinking water collected from specific sources (Snowden 2019; Ambrus, Field and Gonzalez 2020). We now know that the main way of transmission of the 
vibrio cholerae is through the consumption of contaminated food or drink. Across Europe, for much of the nineteenth century water quality, especially in large cities, remained a problem, also due to inefficient or non-existent sewage systems. The situation tended to be worse in the poorest quarters, and John Snow himself argued that beyond the contamination of water supplies, poverty and overcrowding played a major role in spreading the infection (Durey 1979, pp. 66-67).

A recent study of the consequences of cholera on the geography of poverty suggests that while the epicenter of an urban outbreak might not be particularly poor to begin with (as was arguably the case for the Soho quarter in 1854 London), the epidemic itself can cause a persistent shock to value of estate and typology of tenants, enrooting poverty and overcrowding. The conclusion is that "idiosyncratic shocks to individuals can have a permanent effect on the spatial distribution of poverty within a city, even in a thick rental market with few frictions in which only renters are shocked. More broadly, they imply the existence of a simple channel through which we may observe persistence of historic events in any setting" (Ambrus, Field and Gonzalez 2020, p. 507). This has important implications for poverty-related infections like cholera: if relatively poor urban environments favour their spread, and if each outbreak makes those environments poorer and more overcrowded, then there is no way for the residents to escape a kind of "epidemiological poverty trap". The stimulus needed to change this trajectory must come from the outside, for example in the form of urban renewal programs (see further discussion in Section 4.4). The connection between poverty and susceptibility to cholera is well-documented also in recent outbreaks (Anbarci, Escalares and Register 2012; Ali et al. 2015) ${ }^{15}$. Indeed, among the current scourges of the least developed countries, cholera is only one of a range of terrible infections that tend to affect with particular frequency the poor. The list includes, for example, AIDS, tuberculosis and Ebola (Farmer 1996; 2001).

\subsection{Lethal epidemics and the prevalence of the poor}

The example of the quarter of Soho in London after the cholera of 1854, when local impoverishment followed, not preceded, the epidemic calls into question the general connection between severe epidemics and the spread of poverty. If we turn again to the case of plague, there is substantial agreement in the literature that the Black Death led to a reduction in the spread and

\footnotetext{
${ }^{15}$ Cholera continues to infect about 2.9 million people and to cause 95,000 victims every year in countries where it is endemic (as estimated by Ali et al. 2015, p. 10).
} 
in the intensity of poverty. For example, "In England [after the Black Death] households living below the poverty line and unable to afford a respectability basket of consumption goods shrank from over 40 percent of the total in 1290 to fewer than 20 per cent by 1381 [...]. Poverty became more manageable as a problem as its scale diminished [...].” (Campbell 2016, p. 373). This pattern can be easily seen in Figure 9, which also suggests how in this part of the world at least, the preBlack Death conditions, which seem to have been particularly harsh on the poor, probably were never to be encountered again (see Broadberry et al. 2015).

Figure 9. Prevalence of poverty in England, late thirteenth to early nineteenth century (\% of households without income sufficient to ensure access to a 'respectability basket')

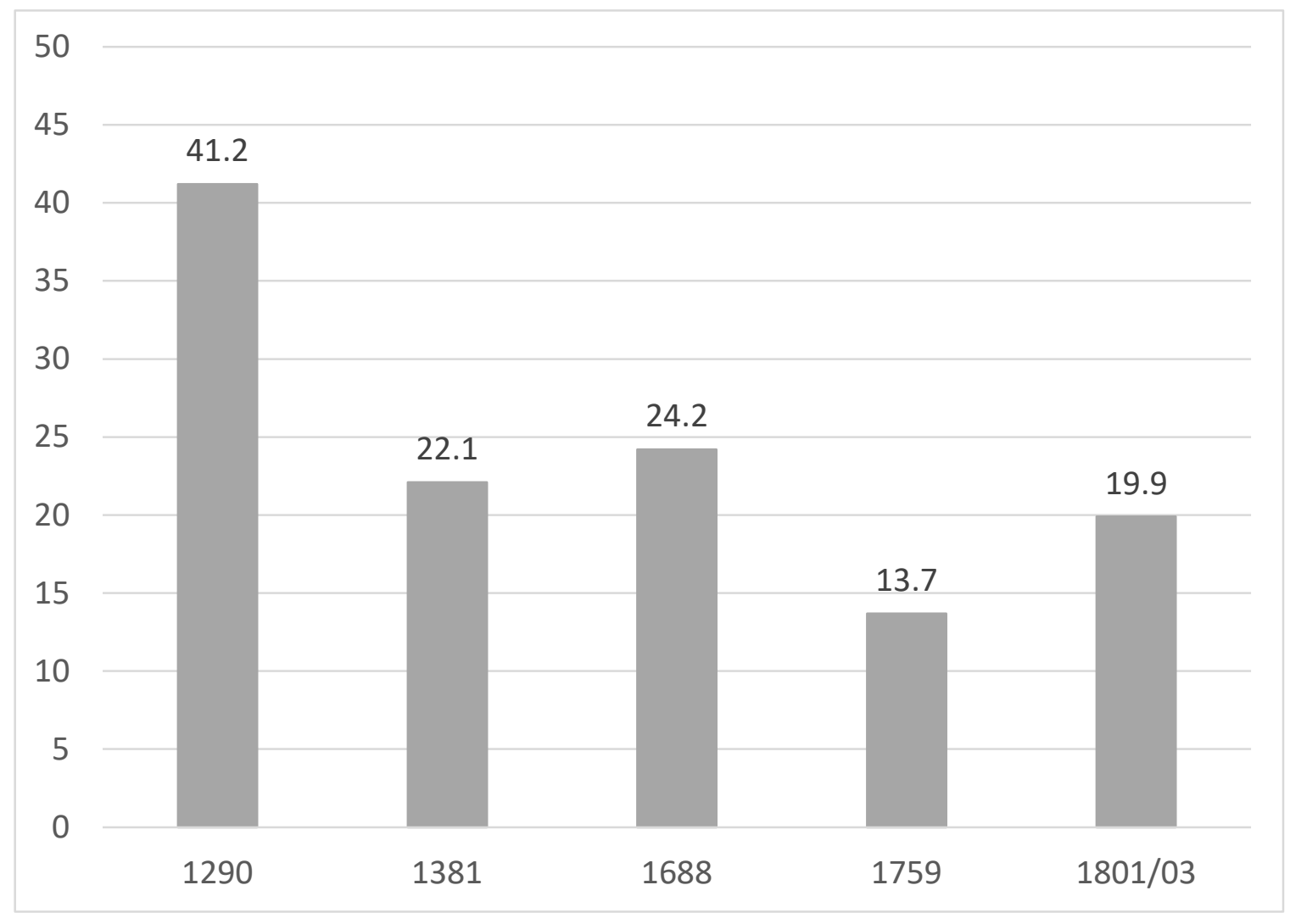

Source: new elaboration from data in Broadberry et al. 2015, p. 329

The ability of the Black Death to reduce the prevalence of the poor can also be shown by measuring relative poverty based on the same distributions used for inequality in Sections 2 and 3, as done 
by a recent comparative study of poverty across Europe from the fourteenth century until ca.1800 (Alfani, Ammannati and Ryckbosch 2020). Note that lacking information about the distribution of income, wealth poverty can be measured. In the following, the approach developed by Alfani and Di Tullio (2019) is used, itself inspired by Azpitarte (2012), and the wealth-poverty line is set at $25 \%$ of the median. A household is considered to be poor when it is placed below the poverty line $\mathrm{e}^{16}$.

For the Black Death period, a decline in relative poverty following the pandemic goes hand in hand with the decline in inequality which has been reported for a selection of communities in Section 2. As an example, in the southern French city of Toulouse, 8.6\% of households were poor in 1335 but by 1398 this was reduced to almost zero. Across Europe, the prevalence of poverty continued to decline in the years immediately following the pandemic. So for example in the city of Cherasco in northwestern Italy, wealth-poor households were $18.2 \%$ of the total around the Black Death, but just $14.9 \%$ at the end of the fourteenth century. For Germany as a whole, it can be estimated (based on data from Alfani, Gierok and Schaff 2020) that the prevalence of wealthpoor households was about $13.5 \%$ around 1350 , falling to less than $5 \%$ by 1400 .

As for inequality, we have more information about the seventeenth-century plagues. Again for Germany, it is possible to estimate that wealth-poor households were about $25 \%$ of the total in 1600, and just 18\% in 1650 after the ravages of both the Thirty Year's War and the plague of 162729. But in other areas, and especially when we lack observations very close to the epidemic under scrutiny, the general trend in the prevalence of poverty looks monotonically growing (Alfani 2020b; Alfani, Ammannati and Ryckbosch 2020) - exactly as has been found for inequality (see Section 3) - or, if a reduction in the prevalence of poverty is to be found, it is very limited and short lived. In the Sabaudian State in northwestern Italy, for example, poor households were about $17 \%$ in 1600 , then declining by just one percentage point by 1650 , presumably because of the 1629-30 plague. The conclusion, then, is largely the same reached for inequality: bar for exceptional cases (like Germany, where however the effects of plague added up to those of the most ravaging of all early modern wars), the seventeenth century plagues had much less capacity

${ }^{16}$ Formally: $\quad P^{H C}(\mathbf{x})=\frac{1}{n} \sum_{i=1}^{n} 1_{x_{i}<\delta}=\frac{p}{n}$

Where $\mathrm{P}(\mathbf{x})$ is the population share of the poor calculated on the distribution $\mathbf{x}, \mathrm{n}$ is the number of households, $p$ the number of poor households, and $\delta$ the relative poverty line; with $1_{x_{i}<\delta}=1$ for $x_{i}<\delta$ and $1_{x_{i}<\delta}=0$ elsewhere. 
than the Black Death to lead to a reduction in the prevalence, and probably also in the intensity, of poverty. The reasons for this difference lie, again, in the deeply mutated context - which was one where, for example, no significant increases in real wages in the post-epidemic years are reported. As a consequence of all this, to simply detect an impact of even the worst seventeenth-century plagues, like the one affecting northern Italy in 1629-30, we must focus on the cases for which we have particularly good information. One such is the Republic of Venice, where we can observe the trends in both absolute, and relative poverty. Additionally, this area was affected particularly severely by the epidemic (the overall mortality rate can be estimated at $40 \%$, higher than the 30 $35 \%$ reported for the North as whole). Following Alfani and Di Tullio (2019), in Figure 10 we take as an estimate for absolute poverty the prevalence of propertyless households -a kind of household that is usually absent from the fiscal records, making the Venetian case quite exceptional-, and we calculate the prevalence of relative poverty based on distributions that exclude the propertyless. This allows us to partially disentangle some of the distributive effects of the epidemic.

Figure 10. Absolute and relative poverty in the Republic of Venice, 1500-1750 (\% of households)

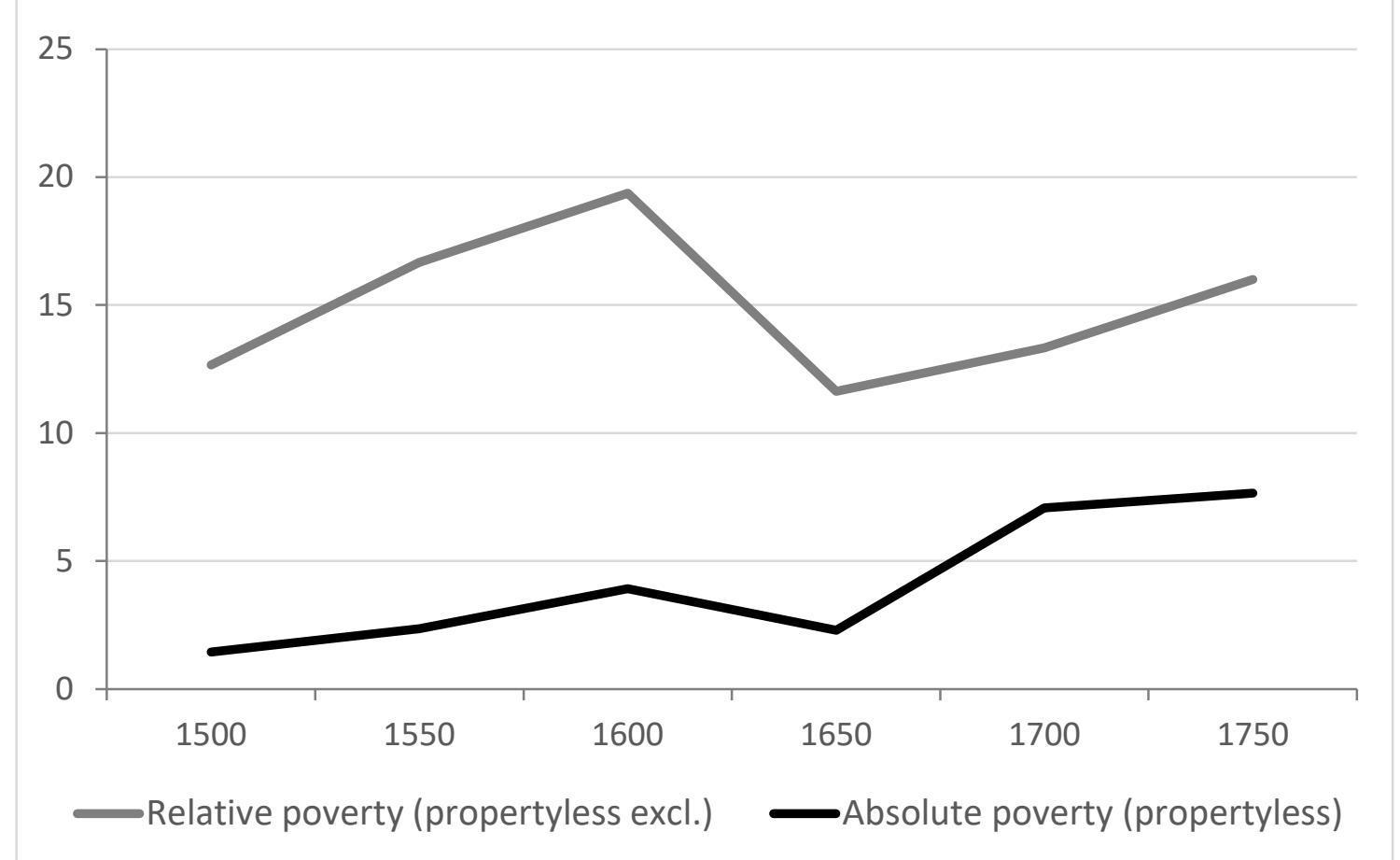

Source: new elaboration based on data from Alfani and Di Tullio 2019 and Alfani, Ammannati and Ryckbosch 2020. 
The figure shows a drop in both absolute and relative poverty in the years immediately following the epidemic: from $3.9 \%$ to $2.3 \%$, and from $19.4 \%$ to $11.6 \%$ respectively between 1600 and 1650 . While a decline in the prevalence of the poor might seem a positive development, a question remains: where did they go? Answering this question means disentangling two very different mechanisms through which a lethal epidemic could reduce both the prevalence of poverty, and the extent of inequality. The first is egalitarian redistribution. If we applied this mechanism to the case of the Republic of Venice, we might hypothesize that the percentage of propertyless households declined because they inherited something (hence they were no longer "propertyless") or because in the mutated post-plague conditions they managed to gain access to some property. In other words, these poor households moved "up", and if we imagine that some shares of overall wealth trickled down from the top to the lower levels (for example because of a boom of inheritances and some inheritance-driven patrimonial fragmentation) at the same time as new households enter the distribution from the bottom, we can easily explain a reduction in relative poverty as well. The problem is that, as discussed in Section 3, in the specific context of North Italy after the 1630 plague this is not a likely scenario, as real wages did not grow, the largest patrimonies were wellprotected from undesirable patrimonial fragmentation, and there was no significant reduction in inequality. So possibly we have to look at the other mechanism, which has to do with selective mortality by socio-economic status. In this case, the percentage of propertyless households declined after 1630 simply because they were decimated, and the same would be true for the prevalence of relative poverty under the reasonable assumption that the individual risk of death was higher, the lower the position in the distribution. This mechanism is consistent with what we know about the selectivity by social-economic status of both plague and cholera. In fact, the decline of inequality in France after 1832 (Figure 8) might be explained by the over-mortality among the poorest strata that has been reported for the year of the epidemic by Rosenthal (2020).

Of course, these mechanisms are not mutually exclusive, so the problem is detecting which one prevailed in each specific event. The Black Death, if truly it did not discriminate (or not much) by socio-economic status, should probably be considered a somewhat "virtuous" example of pandemic-induced reduction in poverty. But probably in most other subsequent lethal epidemics of the preindustrial and early industrial world the darker kind of poverty reduction prevailed, which 
might also explain why reductions in inequality that were achieved by epidemics tended to evaporate very quickly.

\subsection{The role played by institutions and human agency}

The socially-selective character of epidemic mortality does not depend purely on environmental factors (for example, different living conditions) or biological factors, but it is also determined by

institutions and human agency. This is particularly clear in the case of plague:

“institutions $[\ldots]$ actively shifted mortality towards certain specific social-economic groups. From the fifteenth century, most plagues were particularly harsh on the poor. This has to do both with the poor's relatively unhealthy living areas, but also with how they were treated during the epidemics. Once doctors and health authorities noticed that plague mortality tended to be higher in the poorest parts of the city, they began to see the poor themselves as the potential culprits of the spread of the infection. As a result, during the early modern period their presence in cities was increasingly resented [...]. At the onset of a plague, or even as a precautionary measure, vagrants and beggars were expelled. Other poor were isolated in specific places and institutions, often beyond the city walls, where they became easy prey to the infection [...]. Interestingly, the loss of large proportions of the poor was often regarded as one of the few positive consequences of plague. As noted by a friar, Antero Maria di San Bonaventura [...], who was actively involved in fighting the plague in 1656-57 Genoa, « What would the world be, if God did not sometimes touch it with the plague? How could he feed so many people? ...Thus it is necessary to confess that the contagion is the effect of divine providence, for the good governance of the universe.»” (Alfani and Murphy 2017, p. 329).

While is seems certain that the poor run a greater risk of dying during plagues also because of the deliberate action of public health institutions, we have no evidence that the authorities were actively trying to exterminate the poor. So, there is an important difference between this behaviour, and that which led, at the time of the Black Death, to persecute specific groups, and particularly the Jews (Voitgländer and Voth 2012; Finley and Koyama 2016; Jedwab, Johnson, and Koyama 2019a). And yet, a commonality is to be found in how prejudice and ignorance can inform human agency in ways that have relevant consequences in shaping the spread of epidemics and the 
structure of mortality. For the seventeenth-century plagues, this shows in how doctors had come to believe - based on observation, but misunderstanding some crucial facts about how the infection was transmitted- that the poor themselves were a causative factor of the epidemic (Pullan 1992). Centuries later, during a plague outbreak in San Francisco (1900-04), strategies put in place to contain the epidemic were heavily conditioned by prejudice against the local Chinese community, a large part of which was poor and experienced very crowded and unhealthy living conditions Kalisch 1972; Echenberg 2007). This being said, for early industrial times the cholera pandemics remain the best example of events during which the poor might suffer discrimination and as a consequence of this, be subjected to higher mortality compared to other socio-economic groups. For example in Britain during the 1832 cholera outbreak, suspicion spread about vagrants acting as carriers of the infection across the country (which, once again, mimics precisely what has been discussed for plague epidemics). So, under the 1824 Vagrancy Act, "in 1832 rigorous attempts were made to solve the vagrancy problem. 15,000 vagrants were committed to prison, compared with 7,000 in 1825. [...T] here is abundant evidence that in the year of the cholera public opinion was more vigilant and suspicious of the wayfarer. [...] As the numbers of vagrants imprisoned increased in 1832, it can be assumed that this was seen as an effective deterrent, although it increased the chances of cholera outbreaks in houses of correction" (Durey 1979, pp. 35 and 38). Additionally, many local governments enabled policies that not only went against the law, but might at the same time have favoured the spread of cholera nationwide, carried by poor vagrants, and increased the vagrants' own risk of death from cholera and other causes ${ }^{17}$.

While, to some degree, the poor continued to be stigmatized at the time of the cholera pandemics, it must also be underlined that the age of cholera marks a crucial transition towards a much more positive attitude towards them. The observation, that was promptly made by doctors in Europe, in India and elsewhere, that cholera tended to affect in a particularly severe way the poor and more generally those living in unclean and unhealthy environments, quickly led to request for improving their conditions (Durey 1979; Baldwin 1999; Alfani and Melegaro 2010; Harrison 2020). True, this was meant to benefit all strata of society by reducing the circulation of the infection, and partly

\footnotetext{
17 "It was the Edinburgh authorities who acted most decisively outside the law. They set up sanitary cordons on the roads to Haddington and Musselburgh to halt vagrants. Not only was this illegal, it was also against the spirit of the government's recommendations (and, indeed, their own), because it did not actually prevent the poor from travelling" (Durey 1979, p. 36).
} 
the new policies that were introduced were simply redressing past iniquities, for example the huge social-economic divides in access to clean water and facilities for waste disposal that had developed in British cities during the Industrial Revolution (Szreter 1988; Deaton 2003, pp. 132133), a problem that became widespread across the West as well as in India (Harrison 2020) and other world areas. But the fact remains that the poor were ultimately those who benefited most from the advancements in sanitation and in the quality of the urban environment. Indeed, the champions of public intervention to improve the urban environment, like Edwin Chadwick in Britain, were well aware of the broader social implications of the policies that they advocated. As has been observed,

"Sanitationism was a remarkably consistent and unified vision that combined social reform and public hygiene in a seamless whole. All epidemic diseases were to be prevented, or at least ameliorated, in one fell swoop while at the same time social problems were addressed [...]. Housing reform and disease prevention, for example, went hand in hand, part and parcel of the same grand vision of a society that through its concern with public health also improved the lives of its poorest. Hygienic reforms providing all with potable water and efficient waste removal and social change to ensure the poorest what had formerly been a middle-class standard of dwelling and diet: such was the sanitationists' modest prescription for preventing epidemic disease. Best of all, sanitationism was a self-sustaining program of reform that not only improved matters for all, but paid for itself [...]. Over the long haul, the cost of bad hygienic conditions was expected to outstrip that of ameliorating them." (Baldwin 1999, pp. 128-129).

The new situation that had been determined by the emergence of cholera, then, put in motion forces that ultimately led to a reduction in inequalities in health and living conditions ${ }^{18}$. These, in turn, led to improvements across society - as is discussed in the concluding section.

\section{The nineteenth century transition: an escape from poverty and plagues?}

In a famous book, Robert Fogel (2004) argued that the Industrial Revolution finally led the West to overcome Malthusian constraints on development - what he called the "escape from hunger and

\footnotetext{
${ }^{18}$ Something similar happened in San Francisco after the 1900-04 plague: Kalisch 1972.
} 
premature death". Although by 1900 misery was still widespread across western countries, nonetheless the achievements of the nineteenth century had paved the ground for the successes of the twentieth. For Fogel, the main actor in this story was better nutrition, which by allowing for stronger and healthier humans, biologically able to work more and harder, started a virtuous cycle of improvement. In this narrative, declines in morbidity play only a secondary role (they are considered to be themselves mostly the consequence of better nutrition). On this point Fogel followed McKeown (1976; 1979), who had argued that population growth from the eighteenth century and the mortality transition of the nineteenth were not primarily explained by advancements in medicine or public health, but by improvements in nutritional status resulting from economic growth.

It is now broadly recognized that, while surely improvements in nutrition played a crucial role, Fogel was greatly downplaying the importance of declines in morbidity brought forward by factors different from nutrition. For example, as argued by Deaton, "Today, it is clear that public health measures, particularly the provision of clean water and better sanitation (for example, to stop sewage being discharged into drinking supplies), were the fundamental forces for mortality reduction during the century from 1850 to 1950 " (Deaton 2006, p. 110). This, based on a large and growing body of research on the connection between mortality and human environment (especially urban) in a range of world areas (see for example, for Britain, Szreter 1988; 2002; for the United States, Preston and Haynes 1991; Preston 1996; Cutler and Miller 2005). After all, if we look at the paths followed by different causes of death and by life expectancy at birth, it is easy to spot a close correlation between the decline in the prevalence of death from infectious diseases, and growth in life expectancy at birth. In Table 1, this is shown for England and Wales for the period 1850-1935. As can easily be seen, while the percentage of deaths from infectious disease declined, from $26.2 \%$ in 1850 to $3.7 \%$ in 1939 , life expectancy at birth increased dramatically: from 43 to 64 years. Most of the improvement relates to the huge progress achieved on the front of nonrespiratory infections. Comparison of high-income and low-income countries in recent years (2012 in the table) reminds us that non-respiratory infectious diseases continue to be a major obstacle in closing the health gap between the richest and the poorest countries of the world (Deaton 2006; 2013). Incidentally, it also reminds us how much we stand to lose by the emergence of antibioticsresistant pathogens (Ó Gráda 2016) - and by the appearance of new lethal viruses, as Covid-19 is brutally teaching us. 
Table 1. Distribution of causes of death in England and Wales, $1850-1939$

\begin{tabular}{|l|c|c|c|c|c|}
\hline Causes of death & $\begin{array}{c}\text { England and } \\
\text { Wales 1850 }\end{array}$ & $\begin{array}{c}\text { England and } \\
\text { Wales 1900 }\end{array}$ & $\begin{array}{c}\text { England and } \\
\text { Wales 1939 }\end{array}$ & $\begin{array}{c}\text { High-income } \\
\text { countries } \\
2012\end{array}$ & $\begin{array}{c}\text { Low-income } \\
\text { countries } \\
2012\end{array}$ \\
\hline $\begin{array}{l}\text { Infectious } \\
\text { disease, not } \\
\text { respiratory (\%) }\end{array}$ & 26.2 & 18.2 & 3.7 & 2.6 & 28.2 \\
\hline $\begin{array}{l}\text { Infectious } \\
\text { disease, } \\
\text { respiratory (\%) }\end{array}$ & 18.5 & 17.6 & 10.8 & 3.4 & 10.4 \\
\hline $\begin{array}{l}\text { TOT Infectious } \\
\text { diseases (\%) }\end{array}$ & 44.7 & 35.8 & 14.5 & 6.0 & 38.6 \\
\hline $\begin{array}{l}\text { Life expectancy } \\
\text { at birth (years) }\end{array}$ & 43 & 46 & 64 & 79 & 62 \\
\hline
\end{tabular}

Source: elaboration based on data from Ó Gráda 2016

Even those who recognize the importance of declines in morbidity (of the kind not directly resulting from better nutrition) to bring forward substantial improvements in life expectancy tend to overlook something: the role played by the progressive weakening and spacing in time of acute episodes, that is, of pandemics and large-scale epidemics of lethal infections. In this story, the disappearance of plague from Europe, a process which was basically completed by the end of the seventeenth century ${ }^{19}$ (the last plague in Milan dates to 1630, in London to 1665, in Vienna to 1679. Alfani 2013), plays a particularly important role, for two reasons. First, because the end to recurrent plagues led by itself to significant improvements in life expectancy at birth (Livi Bacci 2000; 2017). Secondly, because the disappearance of plague could not be explained with improvements in nutrition, à la Fogel and McKeown, nor more generally with any variable that could reasonably be associated with economic development, including improvements in public

\footnotetext{
${ }^{19}$ Bar some relatively minor outbreaks in the eighteenth and early nineteenth century, all due to re-infection from the broader Mediterranean area (Alfani and Melegaro 2010; Welford 2018).
} 
hygiene which, in the seventeenth century, were yet to come. As a matter of fact, both in its occurrence and in its ultimate disappearance plague is the prototypical exogenous factor, as demographers have neatly clarified: "The plague constitutes a population check largely exogenous, or external, to the sociodemographic system. It acted independently of modes of social organization, levels of development, and so on. The ability of the plague to infect and kill bore no relation to one's [...] level of nutrition.” (Livi Bacci 2017, p. 45). Regarding the reasons for its disappearance, plague remains a mystery (Livi Bacci 2000; Alfani and Murphy 2017), which quite obviously makes it trickier to include its cyclical occurrence and impact in models of long-term economic development.

The occurrence of severe cholera pandemics in the nineteenth century curtailed only partially and temporarily the achievements, in terms of life expectancy, obtained thanks to the disappearance of plague: as has been discussed in Section 3, in the West cholera became a relatively minor scourge already after the end of the fourth pandemic in the 1860s. Differently from plague, cholera fits closely a history of emergence of a new infection, and of its disappearance after appropriate strategies of intervention had been devised. Yet also in the case of cholera, better nutrition did not play a role - improvements in hygiene and sanitation, also in connection with scientific advancements in germ theory, did (Deaton 2003; Snowden 2019). Cholera also serves to remind us of how pandemics are connected to inequality, not only because of their impact on economic inequality, but also because of how they interact with other dimensions of inequality, particular of health and living standards. Indeed, cholera is an excellent example of an infection that not only affected more those experiencing the worst living conditions (and presumably had relatively poor health to begin with), but which also tended to make those conditions worse, potentially paving the ground for further damage to the same groups, and their descendants, in subsequent waves (Ambrus, Field and Gonzalez 2020). This final outcome is quite different compared to major plagues, which did not show the same tendency to enroot poverty, quite the opposite: they tended to reduce the extent of poverty across society - but a crucial component of this epidemic "solution" to the problem of poverty was the direct extermination of the poor.

Compared to the grim reality of preindustrial plague, the history of cholera offers us much more helpful guidelines for fighting, at the same time, the spread of lethal infections and the scourge of poverty: to achieve this objective, direct intervention to improve the living conditions of the 
poorest is also needed, of the kind that, by making them less susceptible to disease, also gives them the opportunity to earn larger incomes and to start a virtuous cycle of development. In other words, the poverty trap, in the past as well as today, has an important epidemiological trait that should be recognized. While this argument surely applies to what currently are the poorest countries in the world (Bloom, Canning and Sevilla 2003; Bonds et al. 2010; Bloom, Kuhn and Prettner 2020), similar concerns have been expressed for rich countries as well. For example, high morbidity among the poor in the United States and, to a lesser degree, in Europe has recently been pointed out by Case and Deaton $(2015 ; 2017)$ as an important contributing factor to a path of "cumulative disadvantage" onto which many low-skill, low-education individuals risk falling, with little or no chance of escape in the absence of external support.

This troubling scenario could be worsened by the appearance of Covid-19. While great care is required when discussing the possible outcomes of a crisis that is still unfolding, it seems clear that, especially in countries where not all have easy and affordable access to health services of good quality and where, more generally, social safety nets are weaker, Covid-19 will tend to lead to higher inequalities: economic for sure, because of growing unemployment especially among the poorest, less-skilled and most economically fragile groups, but also because there seems to be a real risk that many of those who have been infected and developed severe symptoms will suffer permanent damage to their health and physical capabilities - which again, would tend to affect more the ability to generate income of the least educated. Were this the outcome of the current crisis, it would provide further confirmation of a regularity in how past pandemics and major epidemics - surely of plague and cholera, but also of other infections: think about AIDS in subSaharan Africa - affected poverty. They targeted it, made it worse, and only managed to reduce (temporarily) its extent when they proved lethal enough to kill large cohorts of the poor: which, as seen, might have been a more or less acceptable solution to a pressing social problem in the seventeenth century, but surely could not be considered in any way acceptable today.

Luckily enough, there are signs that, in many rich countries, the intention to heed the warning from Covid-19 is spreading. Current plans of the European Union to fund the renewal of national healthcare systems and to build pandemic preparedness could be interpreted in this way. After all, in the worst-affected areas of some rich countries, like Italy, it has already been possible to reasonably predict the damage done by Covid-19 to life expectancy, which is about 2 years of life 
(Blangiardo et al. 2020, p. 6) ${ }^{20}$. This might serve as a stark reminder that, in a crisis of a pandemic nature, we are all in it together - which, as happened after the appearance of cholera in the nineteenth century, might make it easier to build support for ambitious plans to improve society, to the benefit of all. Otherwise, even in rich countries the claim to have escaped poverty might sound empty.

${ }^{20}$ The prediction refers to northwestern Italy and is based on the evidence available at 19 June 2020, hence it is subject to change according to the actual development of the pandemic. Note that within the northwest a high variation across provinces is to be found. In the worst-hit provinces, like Bergamo or Cremona, the predicted loss in life expectancy at birth is of about 5 years under the "moderate" scenario (the loss in life expectancy at year 65 is about 6 years). (Blangiardo et al. 2020, p. 8). 


\section{References}

Alfani, Guido. 2010. "The effects of plague on the distribution of property: Ivrea, Northern Italy 1630." Population Studies 64 (1): 61-75.

Alfani, Guido. 2013. "Plague in seventeenth century Europe and the decline of Italy: an epidemiological hypothesis.” European Review of Economic History 17 (4): 408-430.

Alfani, Guido. 2015. "Economic inequality in northwestern Italy: A long-term view (fourteenth to eighteenth centuries)." Journal of Economic History 75 (4): 1058-96.

Alfani, Guido. 2017. "The rich in historical perspective. Evidence for preindustrial Europe (ca. 1300-1800)." Cliometrica 11 (3): 321-348.

Alfani, Guido. 2020a. "Economic inequality in preindustrial times: Europe and beyond." Journal of Economic Literature, forthcoming

Alfani, Guido. 2020b. "The economic history of poverty, 1450-1800" in The Routledge History of Poverty in Europe, c.1450-1800. David Hitchcock and Julia McClure, eds. London: Routledge, forthcoming.

Alfani, Guido. 2020c. "Pandemics and asymmetric shocks: evidence from the history of plague in Europe and the Mediterranean.” CAGE Working Paper No. 478.

Alfani, Guido, and Francesco Ammannati. 2017. "Long-term trends in economic inequality: the case of the Florentine State, ca. 1300-1800." Economic History Review 70 (4): 1072-1102.

Alfani, Guido, Francesco Ammannati, and Nicoletta Balbo. 2020. "Pandemics and Social Mobility: The case of the Black Death." Working paper

Alfani, Guido, Francesco Ammannati, and Wouter Ryckbosch. 2020. "Poverty in early modern Europe: New approaches to old problems." Working paper.

Alfani, Guido, and Marco Bonetti. 2019. "A survival analysis of the last great European plagues: The case of Nonantola (Northern Italy) in 1630", Population Studies, 73(1): 101-118.

Alfani, Guido, and Matteo Di Tullio. 2019. The Lion's Share. Inequality and the Rise of the Fiscal State in Preindustrial Europe. Cambridge: Cambridge University Press.

Alfani, Guido, Matteo Di Tullio, and Mattia Fochesato. 2020. "The determinants of wealth inequality in the Republic of Venice (1400-1800)." CAGE Working Paper No. 483.

Alfani, Guido, Victoria Gierok, and Felix Schaff. 2020. "Economic inequality in preindustrial Germany, ca. 1300 - 1850.” Stone Center Working Paper Series No. 03.

Alfani, Guido, and Alessia Melegaro. 2010. Pandemie d'Italia. Dalla peste nera all'influenza suina: l'impatto sulla società. Milano: Egea.

Alfani, Guido, and Tommy E. Murphy. 2017. "Plague and Lethal Epidemics in the Pre-Industrial World." Journal of Economic History 77 (1): 314-43.

Alfani, Guido and Cormac Ó Gráda. 2018. "The timing and causes of famines in Europe." Nature Sustainability, 1: 283-288

Alfani, Guido, and Marco Percoco. 2019. "Plague and Long-Term Development: the Lasting Effects of the 1629-30 Epidemic on the Italian Cities." Economic History Review, 72(4): 11751201. 
Ali, Mohammad, Allyson R. Nelson, Anna Lena Lopez, and David A. Sack. 2015. "Updated global burden of cholera in endemic countries." PLoS One Neglected Tropical Diseases 9(6): e0003832.

Álvarez Nogal, Carlos and Leandro Prados de la Escosura. 2013. "The Rise and Fall of Spain (1270-1850)." Economic History Review 66 (1): 1-37

Álvarez Nogal, Carlos, Leandro Prados de la Escosura and Carlos Santiago-Caballero. 2020. "Economic Effects of the Black Death: Spain in European Perspective." EHES Working Paper No. 184.

Ambrus, Attila, Erica Field, and Robert Gonzalez. 2020. "Loss in the Time of Cholera: Long-Run Impact of a Disease Epidemic on the Urban Landscape." American Economic Review 110 (2): 475-525.

Anbarci, Nejat, Monica Escaleras, and Charles A. Register. 2012. "From cholera outbreaks to pandemics: the role of poverty and inequality." The American Economist 57 (1): 21-31.

Arnold, David. 1993. Colonizing the Body. State Medicine and Epidemic Disease in NineteenthCentury India. Berkeley: University of California Press.

Arroyo Abad, Leticia, Elwyn Davies, and Jan Luiten Van Zanden. 2012. "Between conquest and independence: Real wages and demographic change in Spanish America, 1530-1820." Explorations in Economic History 49: 149-166.

Ashworth Underwood, Edgar. 1947. "The History of Cholera in Great Britain." Proceedings of the Royal Society of Medicine 41: 165-173.

Azpitarte, Francisco. 2012. "Measuring poverty using both income and wealth: an empirical comparison of multidimensional approaches using data for the U.S. and Spain." Review of Income and Wealth 58 (1): 24-50.

Barro, Robert, José F. Ursua, and Joanna Weng. 2020. "The coronavirus and the great influenza epidemic - lessons from the 'Spanish Flu' for the coronavirus's potential effects on mortality and economic activity." NBER Working Paper No. 26866.

Beltrán Tapia, Francisco J. and Julio Martinez-Galarraga. 2020. "Inequality and Growth in a Developing Economy: Evidence from Regional Data (Spain, 1860-1930)." Social Science History 44 (1): 169-192.

Blangiardo, Gian Carlo, Roberto Fantozzi, Anita Guelfi, and Valentina Talucci. 2020. Covid-19e scenari di mortalità: un'analisi a livello provinciale. ISTAT, https://www.istat.it/it/files//2020/04/Report Scenari-Mortalit\%C3\%A0 Province 19-giugno2020.pdf

Bloom, David, David Canning and J.P. Sevilla. 2003. "Geography and poverty traps." Journal of Economic Growth 8 (4): 355-378.

Bloom, David E., Michael Kuhn, and Klaus Prettner. 2020. "Macroeconomic Impacts of Modern Infectious Disease Epidemics and Pandemics." Journal of Economic Literature, forthcoming.

Bonds, Matthew H., Donald C. Keenan, Pejman Rohani, and Jeffrey D. Sachs. 2010. "Poverty trap formed by the ecology of infectious diseases." Proceeding of the Royal Society B 277: 1185-1192.

Borgerhoff Mulder, Monique, Samuel Bowles, et al. 2009. "Intergenerational wealth transmission and the dynamics of inequality in small-scale societies." Science 326: 682-8. 
Bourdelais, Patrice. 1987. Une peur bleue: histoire du choléra en France. 1832-1854. Paris: Payot. Bourdelais, Patrice, Michel Demonet, and Jean-Yves Raulot. 1978. "La marche du choléra en France: 1832-1854." Annales. Economies, sociétés, civilisations 33 (1) : 125-142.

Bowles, Samuel, Eric A. Smith, and Monique Borgerhoff Mulder. 2010. "The Emergence and Persistence of Inequality in Premodern Societies.” Current Anthropology 51 (1): 7-17.

Broadberry, Steven, Bruce M.S. Campbell, Alexander Klein, Mark Overton, and Bas Van Leeuwen. 2015. British Economic Growth 1270-1870. Cambridge: Cambridge University Press.

Campbell, Bruce M.S. 2016. The Great Transition. Climate, Disease and Society in the LateMedieval World. Cambridge: Cambridge University Press.

Carter, Michael R., Peter D. Little, Tewodaj Mogues, and Workneh Negatu. 2007. "Poverty traps and natural disasters in Ethiopia and Honduras." World Development 35(5):835-856.

Case, Anne, and Angus Deaton. 2015. "Rising Morbidity and Mortality in Midlife among White Non-Hispanic Americans in the 21st Century." Proceedings of the National Academy of Sciences 112 (49): 15078-83.

Case, Anne, and Angus Deaton. 2017. "Mortality and Morbidity in the 21st Century." Brookings Papers on Economic Activity.

Clark, Gregory. 2016. "Microbes and Markets. Was the Black Death an Economic Revolution?" Journal of Demographic Economics 82: 139-165.

Cohn, Samuel K. 2007. "After the Black Death: Labour Legislation and Attitudes towards Labour in Late-Medieval Western Europe.” Economic History Review 3: 486-512.

Cohn, Samuel K. 2010. "The changing character of plague in Europe, 1348-1800." In Le interazioni fra economia e ambiente biologico. Simonetta Cavaciocchi, ed. Florence: Florence University Press, 33-56.

Cohn, Samuel K., and Guido Alfani. 2007. "Households and Plague in Early Modern Italy." Journal of Interdisciplinary History 38:177-205.

Cummins, Neil. 2017. "Lifespans of the European Elite, 800-1800." Journal of Economic History 77 (2): 406-439.

Cummins, Neil, Morgan Kelly, and Cormac Ó Gráda. 2016. "Living Standards and Plague in London, 1560-1665." Economic History Review 69 (1): 3-34.

Curtis, Daniel R. 2014. Coping with Crisis. The Resilience and Vulnerability of Pre-Industrial Settlements. Farnham: Ashgate.

Cutler, David M., and Grant Miller. 2005. "The Role of Public Health Improvements in Health Advances: The Twentieth-Century United States." Demography 42(1): 1-22.

Deaton, Angus. 2003. "Health, Inequality and Economic Development." Journal of Economic Literature 41: 113-158.

Deaton, Angus. 2006. "The Great Escape: A Review of Robert Fogel's The Escape from Hunger and Premature Death, 1700-2100.” Journal of Economic Literature 44 (1): 106-114.

Deaton, Angus. 2013. The Great Escape: Health, Wealth and the Origins of Inequality. Princeton: Princeton University Press. 
De Keyzer, Maïka. 2018. Inclusive commons and the sustainability of peasant communities in the medieval low countries. New York: Routledge.

DeWitte, Sharon N., and James W. Wood. 2008. "Selectivity of the Black Death with respect to preexisting health.” Proceeding of the National Academy of Science 105:1436-1441.

Durey, Michael. 1979. The Return of the Plague. British Society and the Cholera 1831-2. London: Macmillan.

Echenberg, Myron. 2007. Plague Ports: The Global Urban Impact of Bubonic Plague: 18941901. Sacramento: New York University Press.

Eckert, Edward A. 1996. The Structure of Plagues and Pestilences in Early Modern Europe. Central Europe, 1560-1640. Basel: Karger.

Farmer, Paul. 1996. "Social Inequalities and Emerging Infectious Diseases.” Emerging Infectious Diseases 2 (4).

Farmer, Paul. 2001. Infections and inequalities: the modern plagues. Berkeley, CA: University of California Press.

Fochesato, Mattia. 2018. "Origins or Europe's North-South Divide: Population changes, real wages and the 'Little Divergence' in Early Modern Europe." Explorations in Economic History 70 : 91-131.

Fogel, Robert W. 1994. "Economic Growth, Population Theory, and Physiology: The Bearing of Long-Term Processes on the Making of Economic Policy." American Economic Review 84 (3): 369-395.

Fogel, Robert W. 2004. The Escape from Hunger and Premature Death, 1700-2100. Cambridge: Cambridge University Press.

Fouquet, Roger, and Stephen Broadberry. 2015. "Seven Centuries of European Economic Growth and Decline.” Journal of Economic Perspectives 29 (4): 227-244.

Furió, Antoni, Pau Viciano, Luis Almenar, Lledó Ruiz Domingo, and Guillem Chismol. 2020. "Measuring economic inequality in Southern Europe: the Iberian peninsula in the 14th-17th centuries." In Inequality in pre-industrial societies: causes and effects. Giampiero Nigro, ed.. Firenze: Firenze University Press, Firenze, 169-201.

Galanaud, Pierre, Anne Galanaud, and Patrick Giraudoux. 2015. "Historical Epidemics Cartography Generated by Spatial Analysis: Mapping the Heterogeneity of Three Medieval 'Plagues' in Dijon." PLoS ONE 10(12): e0143866.

Galletta, Sergio, and Tommaso Giommoni. 2020."The Effect of the 1918 Influenza Pandemic on Income Inequality: Evidence from Italy." Working paper, SSRN, 24 http://dx.doi.org/10.2139/ssrn.3634793.

Galor, Oded. 2011, Unified Growth Theory. Princeton: Princeton University Press.

Galor, Oded, and David N. Weil. 2000. "Population, technology and growth: from Malthusian stagnation to the demographic transition and beyond." The American Economic Review 90 (4): 806-27. 
Green, Monica. 2015. Pandemic disease in the Medieval world. Rethinking the Black Death, Kalamazoo: Arc Medieval Press.

Green, Monica. 2018. "Putting Africa on the Black Death map: Narratives from genetics and history." Afriques [En ligne] 9.

Harrison, Mark. 2020. “A Dreadful Scourge: Cholera in early nineteenth-century India.” Modern Asian Studies 54 (2): 502-553.

Jedwab, Remi, Noel D. Johnson, and Mark Koyama. 2019a. "Negative shocks and mass persecutions: evidence from the Black Death." Journal of Economic Growth 24 (4): 345-395.

Jedwab, Remi, Noel D. Johnson, and Mark Koyama. 2019b. "Pandemics, Places, and Populations: Evidence from the Black Death" Technical Report DP13523, C.E.P.R. Discussion Papers.

Johnson, Niall P.A.S, and Juergen Mueller. 2002. "Updating the Accounts: Global mortality of the 1918-1920 'Spanish' Influenza Pandemic.” Bulletin of the History of Medicine 76 (1): 105-115.

Kahn, Matthew. E. 2005. "The death toll from natural disasters: the role of income, geography, and institutions." Review of Economics and Statistics 87(2): 271-284.

Kalisch, Philip A. 1972. "The Black Death in Chinatown: Plague and Politics in San Francisco 1900-1904." Arizona and the West 14 (2): 113- 136.

Kohn, George C. 2007. Encyclopedia of Plague and Pestilence-Third Edition. New York: Facts on File.

Kuznets, Simon. 1955. "Economic Growth and Income Inequality." American Economic Review 45 (1): 1-28.

Last, John M. 2001. A Dictionary of Epidemiology, 4th ed. Oxford: Oxford University Press.

Livi-Bacci, Massimo. 2000. The Population of Europe. Oxford: Blackwell.

Livi Bacci, Massimo. 2006. "The Depopulation of Hispanic America after the Conquest." Population and Development Review 32 (2): 199-232.

Livi Bacci, Massimo. 2017. A Concise History of World Population, Sixth Edition. London: Blackwell.

McKeown Thomas. 1976. The Modern Rise of Population. New York: Academic Press.

McKeown, Thomas. 1979. The Role of Medicine: Dream, Mirage, or Nemesis? Princeton: Princeton University Press.

Milanovic, Branko. 2016. Global Inequality: a new approach for the age of globalization. Cambridge MA: Harvard University Press.

Milanovic, Branko, Peter H. Lindert, and Jeffrey G. Williamson. 2011. "Pre-Industrial Inequality." The Economic Journal 121: 255-72.

Newson, Linda A. 2006. "The Demographic Impact of Colonization." In The Cambridge Economic History of Latin America-Volume 1: The Colonial Era and the Short Nineteenth Century. Victor Bulmer-Thomas, John H. Coatsworth, and Roberto Cortés Conde, eds. Cambridge: Cambridge University Press, 143-84. 
Nunn, Nathan, and Nancy Qian.2010. "The Columbian Exchange: A History of Disease, Food, and Ideas." Journal of Economic Perspectives 24 (2): 163-88.

OECD. 2020. Employment Outlook 2020. Paris: OECD.

Ó Gráda, C. 2016. "Cast Back into the Dark Ages of Medicine? The Challenge of Antimicrobial Resistance.” American Journal of Medical Research 3(1): 142-173.

Pamuk, Şevket. 2007. “The Black Death and the origins of the 'Great Divergence' across Europe, 1300-1600." European Review of Economic History 11: 289-317.

Pamuk, Şevket, and Maya Schatzmiller. 2014. "Plagues, Wages, and Economic Change in the Islamic Middle East, 700-1500.” The Journal of Economic History 74 (1): 196-229.

Piketty, Thomas. 2014. Capital in the Twenty-First Century. Cambridge MA.: Belknap Press of Harvard University Press.

Piketty Thomas, Gilles Postel-Vinay, and Jean-Laurent Rosenthal. 2006. "Wealth concentration in a developing economy: Paris and France, 1807-1994." American Economic Review 96(1):236256.

Piketty Thomas, Gilles Postel-Vinay, and Jean-Laurent Rosenthal. 2014. "Inherited vs self-made wealth: theory and evidence from a rentier society (Paris 1872-1937)." Explorations in Economic History 51:21-40.

Prados de la Escosura, Leandro. 2008. "Inequality, poverty and the Kuznets curve in Spain, 18502000." European Review of Economic History 128: 287-324.

Prados de la Escosura, Leandro, Carlos Álvarez-Nogal, and Carlos Santiago-Caballero. 2020. "Growth Recurring in Preindustrial Spain: Half A Millennium Perspective." EHES Working Paper No. 177.

Preston, Samuel H. 1996. “American Longevity, Past, Present, and Future.” Syracuse University. Maxwell School Center for Policy Research Policy Brief 7/1996.

Preston, Samuel H. and Michael R. Haines. 1991. Fatal Years: Child Mortality in Late Nineteenth Century America. Princeton: Princeton University Press.

Pullan, Brian. 1964. "Wage-Earners and the Venetian Economy." Economic History Review 16 (3): 407-426.

Pullan, Brian. 1992. "Plague and Perceptions of the Poor in Early Modern Italy." In Epidemics and Ideas. Essays on the Historical Perception of Pestilence. Terence Ranger and Paul Slack, eds., 101-123. Cambridge: Cambridge University Press.

Rosenthal, Jean-Laurent, Pandemics and the Economy: Lesson from History, presentation delivered at Caltech, 22 May 2020, https://www.youtube.com/watch?v=ziImAdHziDo

Rota, Mauro, and Jacob Weisdorf. 2020. "Italy and the Little Divergence in Wages and Prices: New Data, New Results." Journal of Economic History, forthcoming.

Ryckbosch, Wouter. 2016. "Economic inequality and growth before the industrial revolution: the case of the Low Countries (fourteenth to nineteenth centuries)." European Review of Economic History 20: 1-22. 
Santiago-Caballero, Carlos. 2011. "Income inequality in central Spain, 1690-1800." Explorations in Economic History 48 (1): 83-96.

Scheidel, Walter. 2017. The Great Leveler: Violence and the History of Inequality from the Stone Age to the Twenty-First Century. Princeton: Princeton University Press.

Slack, Paul. 1985. The impact of plague in Tudor and Stuart England. London: Routledge.

Snowden, Frank M. 2019. Epidemics and Society: From the Black Death to the Present. New Haven: Yale University Press.

Steckel, Richard H. and Carolyn M. Moehling. 2001. "Rising Inequality: Trends in the Distribution of Wealth in Industrializing New England", Journal of Economic History 61 (1): 160-183.

Szreter, Simon. 1988. "The Importance of Social Intervention in Britain's Mortality Decline c.1850-1914." Social History of Medicine 1 (1): 1-38.

Szreter, Simon. 2002. "Rethinking McKeown: The Relationship Between Public Health and Social Change." American Journal of Public Health 92 (5): 722-725.

Van Bavel, Bas. 2020. "Looking for the islands of equality in a sea of inequality. Why did some societies in pre-industrial Europe have relatively low levels of wealth inequality?" In Inequality in pre-industrial societies: causes and effects. Giampiero Nigro, ed.. Firenze: Firenze University Press, Firenze, 169-201.

Van Bavel, Bas, Daniel R. Curtis, and Tim Soens. 2018. "Economic inequality and institutional adaptation in response to flood hazards: a historical analysis." Ecology and Society 23(4): 30.

Van Bavel, Bas, Daniel R. Curtis, Jessica Dijkman, Matthew Hannaford, Maïka de Keyzer, Eline van Onacker, and Tim Soens. 2020. Disasters and History. The Vulnerability and Resilience of Past Societies. Cambridge: Cambridge University Press.

Van Zanden, Jan Luiten. 2009. The Long Road to the Industrial Revolution. Brill: Leiden.

Welford, Mark. 2018. Geographies of Plague Pandemics. New York: Routledge.

Whittles, Lilith K. and Xavier Didelot. 2016. "Epidemiological analysis of the Eyam plague outbreak of 1665-1666." Proceedings of the Royal Society B: Biological Sciences 283: 20160618.

Williamson, Jeffrey G. 1997. "Globalization and inequality, past and present." World Bank Research Observer 12 (2): 117-135.

Williamson, Jeffrey G. 2010. "Five Centuries of Latin American Inequality." Journal of Iberian and Latin American Economic History 28 (2): 227-252.

Ziegler, Michelle. 2015. "The Black Death and the Future of the Plague." In Pandemic Disease in the Medieval World. Rethinking the Black Death. Monica H. Green, ed. 259-283. Kalamazoo: Arc Medieval Press. 